Article

\title{
Towards Rail-Road Online Exchange Platforms in EU-Freight Transportation Markets: An Analysis of Matching Supply and Demand in Multimodal Services
}

\author{
Anuradha Jain ${ }^{1, *}$, Rob van der Heijden ${ }^{2}$, Vincent Marchau ${ }^{2}$ and Dirk Bruckmann ${ }^{3}$ \\ 1 Institute of Management Research, Radboud University, 4125 Riehen, Switzerland \\ 2 Institute for Management Research, Radboud University, 6500 HK Nijmegen, The Netherlands; \\ r.vanderheijden@fm.ru.nl (R.v.d.H.); v.marchau@fm.ru.nl (V.M.) \\ 3 Faculty of Communication and Environment, Rhine-Waal University of Applied Sciences, \\ 47475 Kamp-Lintfort, Germany; Dirk.Bruckmann@hochschule-rhein-waal.de \\ * Correspondence: anu.jain@ajps.ch
}

Received: 9 November 2020; Accepted: 8 December 2020; Published: 10 December 2020

\begin{abstract}
The European Union (EU) is confronted with too low a share of inland rail freight transport. The implementation of two-sided online exchanges for rail-road freight transport could increase this share. However, such exchanges focusing on the EU market are mainly designed for single modes of transport. Their matching of supply and demand for multimodal services, especially including rail, is still in its infancy. This paper applies a maturity growth framework to speed up the implementation of such multimodal online exchanges. The framework integrates insights from industrial organization theory, platform economy theory, and maturity growth theory. Online exchanges, summarized in a new taxonomy, are compared to study their practices on matching supply with demand on the exchange, especially for multimodal services. Data is collected from case studies, exchange websites and semi-structured interviews. The analysis shows the emergence of new market actors and business models, including digital freight forwarders. These offer a variety of transport mode solutions for EU inland and EU related global freight transport. Maturity in matching supply and demand appears to result from clear objectives to provide benefits to the exchange participants, notably by digitizing the data for transaction completion and providing real time support for operational issues. In this context of rising online exchanges, especially in road and global multimodal transport (air, ocean, and road), the competition to capture a fragmented freight market seems to steadily increase. A similar maturity analysis of exchanges could not be found.
\end{abstract}

Keywords: multimodal freight transport; online exchange platform; matching supply and demand; maturity

\section{Introduction}

Rail freight transport in the EU-28 countries has been facing challenges in increasing its market share in terms of transport volume since 2011 (18.7\% in 2011, 18.0\% in 2018 in EU inland freight transport) [1]. This conflicts with the European Union (EU) white paper policy goals to shift $30 \%$ of the long-distance road freight transport beyond $300 \mathrm{~km}$ to multimodal transport by 2030 and more than $50 \%$ by 2050 . Consequently, the freight transportation service industry has to innovate itself in order to become more sustainable. One way to do that is to introduce digital service platforms [2].

A special subset of digital platforms concerns two-sided multimodal online exchanges, linking service providers at one side (supply) with service consumers at the other side (demand). Such exchanges in other network industries typically facilitate the efficient and smooth matching of supply of and demand for the industries' services. Thus, lessons learned from network industries inside 
and outside the freight transport sector can be helpful in conceptualizing and implementing multimodal online freight transport exchanges (called FTE from here on) for contributing to a sustainable growth of rail transport by integrating it with road transport.

The implementation of such FTEs is complex, due to the uncertainty on how they will affect the structure and performance of the freight transportation industry. This uncertainty is due to the involvement of multiple stakeholders that often have competing business interests and are required to collaborate on the online exchange by sharing information, their benefits, and risks. Industrial organization theory [3] in this regard claims that (de)regulation and technological innovation are change drivers influencing the market structure, the behavior, and the performance of network industries. Research shows that the implementation of FTEs requires intensive collaboration between stakeholders, based on an balanced business model with benefits for both sides [4-7].

Conceptualizing and implementing such an approach is a gradual and complex process following different stages of transition [8]. For understanding this process, a basic maturity framework for online exchanges was presented in [9]. The framework was based on a study of characteristics of various network industries (capacity management, transport services, infrastructural and market conditions, regulation, etc.) (see also [10]). Although the analysis focused on the coping with regulatory topics that can possibly improve rail freight integration in multimodal freight transport, among others it was also concluded that for multimodality the standardization of products is essential. A further elaborated version of the maturity framework, is labelled as the Online Exchange Maturity Framework (OEMF) and described in [11]. The framework is based on the idea of maturity growth of involved firms, inspired by the Capability Maturity Model [8].

The basic maturity framework in [9] was applied for comparing online exchanges for rail freight transport services, with online exchanges of network industries with similar characteristics, notably electricity, gas, long distance passenger rail transport and urban public transport. Both road and rail FTEs in the EU turned out to be less mature than online exchanges in other industries, as their current practices are limited to only connecting the two sides of the FTEs (e.g., shippers to carriers) for their respective modes. This does not fulfil the definition of an exchange, which assumes that the two sides come together for also a smooth process of price discovery [12] and contracting [10,11]. Consequently, the continuous and strong demand for low-cost mode integration in freight transportation [13,14], that is dynamically affected by changing external circumstances (e.g., pandemic crises, environmental restrictions, or geo-political tensions), is not satisfactorily fulfilled. Especially cross-border freight transport business requires extensive coordination between multiple actors for freight handling, customs, security, and insurance at various stages [15]. Since the previously studied online exchanges do not appear to yet solve key challenges of organizing multimodal freight transport, this paper explores how online exchanges in other freight transportation industries to bring the matching of supply and demand of multimodal services to a higher level of performance. The paper applies the aforementioned OEMF to answer the following two research questions (RQ):

RQ1: What is the state of online exchanges in the freight transportation industry regarding matching of services for (a) single mode transport and (b) multimodal transport?

RQ2: What learnings can be drawn on maturity of these exchanges regarding the mechanisms for matching of supply and demand, especially for multimodal freight transport services?

RQ1 thus explores the landscape of online exchanges in the freight transportation industry, whereas RQ2 assesses their performance to learn for the future development of such exchanges.

The outline of this paper is as follows. Section 2 presents the theoretical framework that is used for studying the implementation of online exchanges. Next, Section 3 discusses the methods applied, within this framework, to answer the two research questions presented above. Section 4 presents the results of the analyses and Section 5 deals with conclusions and a discussion. 


\section{Theoretical Framework}

\subsection{Definition of Online Exchanges in Freight Transport}

Many definitions of online exchanges can be found in literature [16]. This research adopted the definition that an online exchange, operating as a third party, applies a matching mechanism to bring buyers (demand side) and sellers (supply side) together in a virtual place (platform). Here, they interactively negotiate an acceptable price for a product or service at a given time on a dynamic basis [12] and on finalization of the transaction a binding contract is organized by the online exchange based on this price discovery mechanism $[10,11]$.

In the context of freight transport, the demand side of the freight transport exchange (FTE), relates to shippers and the supply side to carriers. Both are considered as participants on the FTE. Presently, freight forwarders and other businesses in the supply chain increasingly tend to participate on the demand side of the online exchanges. Moreover, the rise of a new market entrant in the logistics market can be observed. These are the "Digital freight forwarders" (DFFs), which, similar to FTEs, also offer benefits to the aforementioned participants through matching [17]. Both the FTE and DFF should be considered as a subset of online exchanges. Since there are similarities but also significant differences in their business models and services, this paper develops a new taxonomy in Section 4 for the purpose of comparing the online exchanges. Such a taxonomy was not found in the literature till now. When not mentioned otherwise, this paper uses the term "online exchange" as a generic term while referring to both taxonomies in the freight transport industry.

\subsection{The Online Exchange Maturity Framework Applied}

To learn about maturity of practices of online exchanges regarding matching of demand and supply, the theoretical framework OEMF is applied. Here, only a brief summary of the OEMF will be discussed (see for more details: [11]). The framework, as shown in Figure 1, builds upon three theories: industrial organization theory, platform economy theory, and maturity growth theory.

From industrial organization theory two ideas have been adopted for the OEMF. The first idea is that of structure-conduct-performance linkages [3] for understanding behavior and performance of practices of online exchanges, within the current market structure and its context (e.g., state of regulation and technological innovation). A practice is a set of related activities that contribute to the effective implementation of an exchange's key processes. The second idea is that due to path-dependency an understanding of past behavior is important for improving insights on current behavior and assessing the present capabilities of industries. This idea is stressed in e.g., the industry dynamics framework [18,19]. Online exchanges must continuously develop and improve practices based on the following three types of capabilities in order to grow in maturity [18]:

i. Market related capabilities concerning the capability to make strategic decisions regarding the exchange's development, e.g., its market focus and the definition of products and services, that are driven from market requirements;

ii. Operational capabilities concerning the capability to achieve prerequisites (e.g., standardization of processes and business policies, learning, training) and implement strategic decisions for coordinating business related activities, both within the exchange and outside the exchange, e.g., with external partners;

iii. Technical capabilities concerning the capability to innovate and better support customers in the market, e.g., in terms of facilitating transactions.

These three types of capabilities are needed to perform practices related to the key processes of the online exchange. These so called key process areas (KPAs) are indicated in Figure 1 as the market related KPA, the operational KPA and the technical KPA. Since the change above referred to is a complex process, a brief overview of the number of online exchanges in the industry and their level of 
performance, can be supportive in understanding the states of online exchanges in terms of level of competition and their role in the freight transportation industry.

The second, inspiring theory is platform economy theory, applied for better understanding of collaborative behaviour that online exchanges show in their practices for delivering benefits to both sides [7,17,20-22]. Such a behaviour relates to practices (summarized in Figure 1) to incentivize supply and demand side to join the exchange. The exchange, through innovative algorithms, continuously improves and balances the consumption of these services by matching the need of the demand side to the supply side that provides the services agreed upon. The interaction regarding these services is designed in such a way that both sides of the exchange remain triggered to collaborate on the exchange. Higher numbers of matches finalized as transactions lead to improvement in common benefit to all participants and can thus be considered as a positive network effect. Such an effect has the potential to accelerate the interactions on the exchange [7].

Finally, the maturity growth theory [8] was applied to understand the varying levels of performance of practices (as indicated in Figure 1 in terms of the three levels, create, curate, and cultivate) and the challenges for transition to a higher maturity. Distinguishing between different maturity levels is the basis for understanding the process of improvement of online exchanges as suggested by platform theory, although the number of levels assumed in this literature differ from three [22] to six (e.g., [23]). The common assumption in these studies is that actors are collaboratively willing to make such a transition, provided their interests and risks can be balanced through a viable value proposition. In Figure 1, examples of generic key performance indicators (KPI) to measure the performance of practices at the, in this study, distinguished three levels of maturity serve as (non-exclusive) guidelines. The assessment of maturity of different KPAs is the basis for an overall assessment of maturity for the studied exchanges.

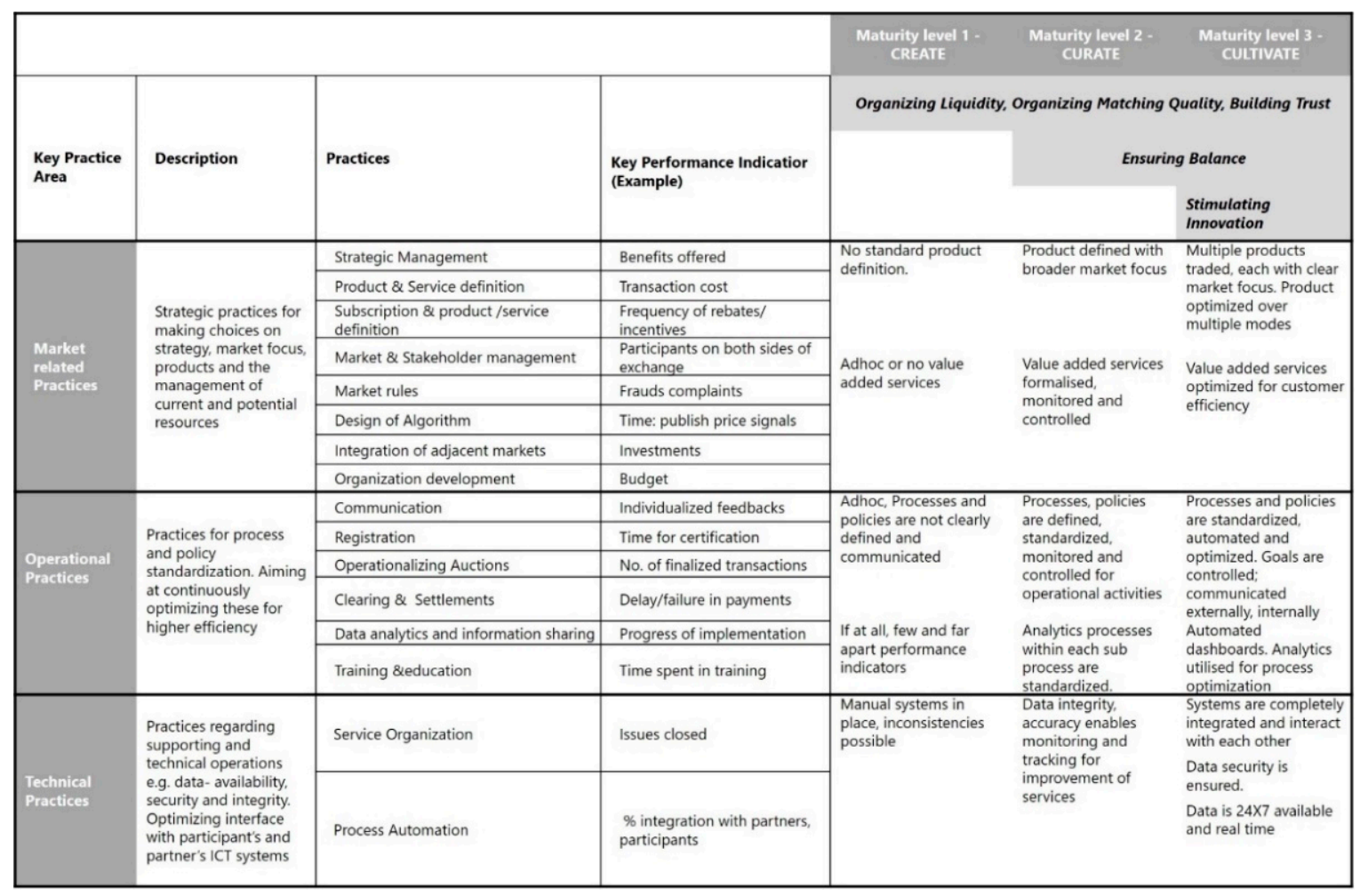

Figure 1. Theoretical framework for maturity assessment of online exchanges (Source: Jain, 2020).

\section{Methodology}

This section describes the research process followed to answer the two research questions. RQ1 focuses on the state of online exchanges by looking into their business models, for single mode as 
well as multimodal transportation services. Based on this overview, exchanges are selected for RQ2 to draw learnings by performing the maturity assessment on their practices with regards to the matching of supply and demand of multimodal services. The first step in this section (Section 3.1) is to specify the criteria for selecting relevant online exchanges for the intended analysis. The second step (Section 3.2) elaborates on the data collection and in the third step (Section 3.3) the type of analyses is described.

\subsection{Definition of Selection Criteria for Relevant Online Exchanges}

The criteria for selecting online exchanges are based on the conceptual framework, the OEMF. This framework focuses on different attributes of business models for all online exchanges. Specificities of these exchanges come from the range of features each attribute can take. A combination of these features characterizes a specific business model of an online exchange and constitutes the basis for a comparison of these exchanges and their practices [24]. From a maturity growth perspective, exchanges improve their capabilities to perform certain practices by repeatedly applying the activities associated with these practices. By setting higher goals for practices and developing the required underlying capabilities, transitioning is possible from ad hoc activities towards an ongoing process of innovation (e.g., technological innovation). In terms of improving maturity this implies: learning to standardize, then automate, and finally monitor and control the activities in such a manner that these can be optimized for providing benefits to participants of the online exchange on both sides [8].

Based on this conceptualization, the selection criteria for identifying online exchanges in the freight transportation industry that (a) offer a representative state-of-the-art overview (RQ1) and (b) potentially offer lessons on maturity growth (RQ2), are presented in Figure 2, and described below.

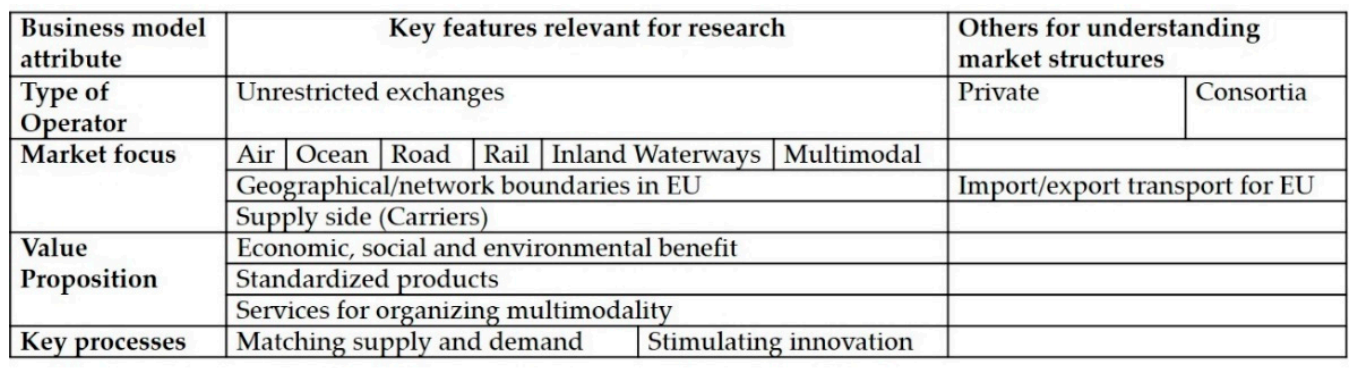

Figure 2. Criteria for selecting online FTEs.

(i) Type of operator: describes the level of autonomy an online exchange has in making decisions. Unrestricted, private, and consortia exchanges are studied in RQ1. The latter two are initiated by incumbent freight forwarders as a response to competition from unrestricted exchanges [2], and explored only in relation to RQ1. For RQ2, the focus is merely on the unrestricted online exchanges because they have the highest level of autonomy in their decision making.

(ii) Market focus: defines the boundaries of customer segments an exchange aims to cater to, and are not easy to define [20]. Especially geographical network/ boundaries offer insight into the extent of network (market) access of an exchange [2]. This is crucial in freight, as rules differ across borders [25]. Following the research aim, online exchanges for freight transport modes beyond rail and road, i.e., ocean, air, inland waterways, and multimodal transport are selected for comparison. This implies expanding the geographical boundaries from EU inland transport to import/export freight transport.

(iii) Value proposition: describes the benefits that online exchanges provide to their stakeholders (i.e., owners, participants, society etc.) e.g., in economic (e.g., cost savings, market access), social (e.g., reduction in traffic congestion, ensuring that suppliers follow fair working conditions) and environmental (e.g., reduced emissions) terms. Based on previous analyses [9], benefits can be maximized by using standardized products (e.g., commodities) to facilitate multiple interactions on the exchange, or organizing multimodality (e.g., for optimal use of transport assets). 
(iv) Key processes: online exchanges can take off when they have organized sufficient liquidity (critical mass) on the exchange [21,24], notably by gaining trust in the markets [22]. This relates to the lowest maturity level in the OEMF, labelled as create. Online exchanges by definition have to fulfil this basic requirement, but differ in the degree to which they are successful in this. The challenge in the present analysis is to learn from online exchanges with higher maturity levels, that is either at the curate level (requiring next to liquidity a high matching quality and ensuring balance in service consumption on both sides of exchange) or at the cultivate level (that adds systematic efforts to innovate for expanding to new markets). Since the create level of maturity represents a basic maturity, it is not relevant for the selection as it offers no potential learnings for reaching a higher maturity.

The application of these selection criteria enables to select a representative sample to answer RQ1 understanding the current state of online exchanges in the freight transportation industry. The selection of unrestricted online exchanges is presented in Table 1. In addition, Table 2 presents the selection of private online exchanges (referring to the above discussed selection criterion 'type of operator'; consortia were not found) that were also explored in relation to RQ1.

The unrestricted online exchanges included in Table 1 also serve as the sample of exchanges for performing the more in-depth maturity assessment aimed at in RQ2.

\subsection{Data Collection}

Different methods were applied for data collection. Using the criteria described in Section 3.1 in relation to RQ1, a review of scientific literature was performed for finding online exchanges in the freight transport industry, both for single mode and multimodal services $[2,17,26]$. Further, different sources on benchmarks were explored for finding these exchanges e.g., market reports, reported case studies [27-29] and research databases (such as Crunchbase.com) on firms were consulted to cross check the data from the literature. Together with information collected in previous interviews [9], this enabled to apply a snowballing strategy to create a representative population for answering RQ1.

In relation to RQ2, additional data was needed to enable an assessment of maturity levels of practices of the sample of online exchanges. Therefore, more in-depth data was retrieved from their websites and reported cases were studied. Evidently, one has to be aware of the fact that information offered on websites might not fully match with the actual situation; however, since our research focuses on understanding general trends in the emerging online exchanges and their business models, this quality of information is considered acceptable. The semi-structured interviews that were organized with experts and stakeholders in selected exchanges, with much knowledge about the sampled exchanges, are assumed supportive in compensating the possible lower data quality.

The semi-structured interviews focused on the interviewees' opinion on differences between FTEs and DFFs, in terms of benefits, challenges, requirements, and expectations. Further, aims and requirements on cooperation between rail and road for their business and on online exchanges were explored. These interviews included closed and open questions. The closed questions notably served a face validity check on the patterns emerging from the analysis of website information and written documents. The open questions allowed us to gain new insights and opinions of the interviewees on opportunities and threats for online exchanges in the freight transportation industry [30]. The choice of interviewees aimed to find experts with a clear system view and with a deep understanding of emerging developments based on different perspectives and experiences. Such experts in practice are scarce. They were representatives in Europe from a rail freight carrier (1), a global shipper (1), a road transport association (an online exchange expert) (1), an intermodal freight forwarding firm (1), and an enterprise involved in technological innovation for logistics services in multimodal transport (1). 
Table 1. Online Exchanges (digital freight forwarders and freight transport exchanges, Type of operator = unrestricted) for single transport mode and multimodal services operating in EU, and offering unrestricted access to customers. Authors depiction based on [2,17,26-28], Crunchbase.com and interviews.

\begin{tabular}{|c|c|c|c|c|c|c|c|c|}
\hline $\begin{array}{c}\text { Name of } \\
\text { Exchange/Head } \\
\text { Office/Website }\end{array}$ & DFF/FTE & $\begin{array}{c}\text { Multimodal or Single } \\
\text { Mode/(for Profit, Owns Asset: } \\
\text { Y/N)/Market Focus }\end{array}$ & $\begin{array}{l}\text { Lead, Total } \\
\text { Investors }\end{array}$ & Founded & $\begin{array}{l}\text { Funding } \\
\text { (Million) }\end{array}$ & $\begin{array}{l}\text { Geographical } \\
\text { Focus }\end{array}$ & $\begin{array}{c}\text { Liquidity } \\
\mathrm{K}=1000 \\
\mathrm{M}=1000 \mathrm{~K}\end{array}$ & $\begin{array}{l}\text { Mode Based Product } \\
\text { (Commodity Unit) }\end{array}$ \\
\hline $\begin{array}{c}\text { Freightos, US } \\
\text { www.freightos.com }\end{array}$ & FTE & $\begin{array}{l}\text { Multimodal, (Yes, No), } \\
\text { Logistics industry, } \\
\text { freight forwarders }\end{array}$ & 5,12 & 2012 & $\$ 92.7$ & $\begin{array}{l}\text { (Possibly) } \\
\text { Worldwide }\end{array}$ & $\begin{array}{l}8 \mathrm{M} \text { quotes, } 75+ \\
\text { Freight forwarders }\end{array}$ & $\begin{array}{l}\text { Ocean, Air and Road, } \\
\text { Multimodal }{ }^{1} \text {. LCL, } \\
\text { FCL boxes/pallets }\end{array}$ \\
\hline $\begin{array}{c}\text { Flexport, US } \\
\text { www.flexport.com }\end{array}$ & DFF & $\begin{array}{l}\text { Multimodal, (Yes, Yes), } \\
\text { Supply chain customers }\end{array}$ & 4,6 & 2013 & $\$ 1300$ & Worldwide & $10 \mathrm{~K}$ logistic teams & $\begin{array}{l}\text { Ocean, Air, Road/LCL, } \\
\text { FCL }\end{array}$ \\
\hline $\begin{array}{l}\text { Forto, Germany } \\
\text { www.forto.de }\end{array}$ & DFF & $\begin{array}{l}\text { Multimodal, (Yes, No), } \\
\text { Supply chain customers }\end{array}$ & $4,9^{2}$ & 2016 & $\$ 53$ & Europe, Asia & $1.5 \mathrm{~K}$ customers & $\begin{array}{l}\text { Ocean, Air, Rail }{ }^{3}, \\
\text { Multimodal/LCL, FCL }\end{array}$ \\
\hline $\begin{array}{l}\text { Cargo.one, Germany } \\
\text { www.cargone.com }\end{array}$ & FTE & $\begin{array}{c}\text { Single, (Yes, No), B2B } \\
\text { International freight } \\
\text { forwarders and air carriers }\end{array}$ & $2,3^{4}$ & 2017 & $\$ 3.2$ & Worldwide & $\begin{array}{l}>300 \text { freight } \\
\text { forwarding } \\
\text { customers }\end{array}$ & $\begin{array}{l}\text { Air, Shipment pieces } \\
\text { from } 1 \mathrm{Kg} \text { to } 10 \text { tons }\end{array}$ \\
\hline $\begin{array}{l}\text { Sennder, Germany } \\
\text { www.sennder.com }\end{array}$ & DFF & $\begin{array}{c}\text { Single, (Yes, No), } \\
\text { Shippers and carriers }\end{array}$ & 3,10 & 2015 & $\$ 100$ & Europe & $>7.5 \mathrm{~K}$ Trucks & Road, FTL \\
\hline $\begin{array}{l}\text { Cargonexx, Germany } \\
\text { www.cargonexx.com }\end{array}$ & DFF & $\begin{array}{l}\text { Single, (Yes, Yes), Shippers and } \\
\text { carriers (spot) in refrigerated } \\
\text { and dangerous goods }\end{array}$ & n.a. & 2016 & $\$ 6$ & Europe & $>\mathrm{K}$ firms & Road, FTL, Pallets \\
\hline $\begin{array}{l}\text { InstaFreight, Germany } \\
\text { www.InstaFreight.com }\end{array}$ & DFF & $\begin{array}{l}\text { Single, Yes, Yes, B2B shippers } \\
\text { and carriers }\end{array}$ & 1,1 & 2016 & $\$ 8$ & EU & $\begin{array}{l}>0 \mathrm{~K} \text { carriers } \\
>40 \mathrm{~K} \text { orders }\end{array}$ & Road ${ }^{5} /$ FTL and Pallets \\
\hline
\end{tabular}

goods consolidated by DFF. Abbreviations: Y/N: Yes/No, n.a. Not Available, FCL (Full Container Load), LCL (Less than a Container Load), FTL (Full Truck Load). 
Table 2. Private online exchanges (digital freight forwarders and freight exchanges) for single transport mode and multimodal operating in EU; belonging to incumbents. Authors' depiction based on [2,17,26-28].

\begin{tabular}{|c|c|c|c|c|c|c|c|}
\hline Name of Exchange/Location/Website & DFF/FTE & Owner & Founded & Funding & Geographical Focus & $\begin{array}{l}\text { Liquidity } \\
K=1000\end{array}$ & Product (Commodity Unit) \\
\hline $\begin{array}{l}\text { Drive4Schenker, Germany, } \\
\text { D4s.dbschenker.com }\end{array}$ & FTE & DB Schenker & 2017 & n.a. & Europe & $5 \mathrm{~K}$ loads/day & Road/ FTL and LTL \\
\hline $\begin{array}{l}\text { mykN, Switzerland, } \\
\text { www.kn-portal.com }\end{array}$ & DFF & $\begin{array}{l}\text { Kuehne }+ \\
\text { Nagel }\end{array}$ & 2018 & n.a. & Worldwide & n.a. & $\begin{array}{c}\text { Ocean, Air }{ }^{2} \text { / FCL (Ocean), } \\
\text { Packets (Ocean) }\end{array}$ \\
\hline $\begin{array}{l}\text { Twill, Denmark, } \\
\text { www.twill.net }\end{array}$ & DFF & Maersk & 2013 & n.a. & Worldwide & n.a. & $\begin{array}{l}\text { Ocean, Barge, Road, rail/ } \\
\text { Containers }\end{array}$ \\
\hline $\begin{array}{c}\text { LOADS TODAY, Austria, } \\
\text { www.lkw-walter.com }\end{array}$ & FTE & LKW Walter & 2016 & n.a. & Europe & n.a. & Road, FTL, combined traffic \\
\hline $\begin{array}{l}\text { Traigo, Germany, } \\
\text { Traigo.com }\end{array}$ & FTE & VTG AG & $2020^{1}$ & n.a. & Europe & n.a. & Rail/Wagon \\
\hline $\begin{array}{l}\text { Saloodo!,Germany } \\
\text { www.saloodo.com }\end{array}$ & Both ${ }^{3}$ & DHL & 2016 & n.a. & 35 countries 4 & $\begin{array}{l}12 \mathrm{~K} \text { carriers, } \\
30 \mathrm{~K} \text { shippers }\end{array}$ & Road/ FTL, LTL, Partial \\
\hline
\end{tabular}




\subsection{Analysis}

In order to answer RQ1, a comparative analysis of the business models of the online exchanges included in Table 1 was made, as well as for the private exchanges included in Table 2 as far as information could be found on these. The comparison resulted in a first shift between multimodal exchanges (FTEs and DFFs) and single mode exchanges (FTEs and DFFs), as indicated in the tables. For RQ2, the analyses of selected online exchanges particularly focused on the heuristics and the role of technical innovation for the matching of supply and demand on online exchanges. Required information was based on the scarce literature available on this topic [2,17,26], market reports, case studies [27-29], along with information from performed interviews that aimed at corroborating and complementing the information from other sources. The related practices of the selected exchanges were assessed in terms of maturity Levels 1 (create), Level 2 (curate), and Level 3 (cultivate), following the OEMF. Refinements and new additions for the framework were documented.

The details of the analyses are further described in Section 4.

\section{Results}

Section 4.1 first discusses the findings for the analysis related to RQ1. The focus is on the current state of the freight transport industry regarding online exchanges. In line with the OEMF, the overview focuses on which and how online exchanges bring the matching of supply and demand to a higher level (in single mode transport and multimodal transport). Further, if so, any significant differences in their business models are made visible. Next, Section 4.2 answers RQ2, by focusing on the key learnings for rail freight based on a maturity assessment of the selected online exchanges.

\section{1. $R Q 1$}

The unrestricted exchanges in Table 1 are the main focus of the analysis. The private online exchanges in Table 2 are merely briefly overviewed to understand the current state of the industry.

We first study the unrestricted online exchanges in Table 1, i.e., Freightos (multimodal FTE), Forto and Flexport (multimodal DFFs), Cargo.one (Aviation FTE), InstaFreight, Cargonexx, and Sennder (Road DFFs). These FTEs and DFFs, for single mode European inland transport (air, road) and multimodal transport (mainly ocean, air, and road) focusing on global/international transport, have been launched as start-ups and developed up to a relatively stable operational level. Hence, they confirm the emergence of online exchanges in the past decade.

In line with industrial organization theory, competition amongst them can be observed, with each exchange focusing on its specific niche [31], e.g., Forto is a vertically integrated freight forwarding platform with key focus in rail services currently relating to transport between China and Europe [32]. Freightos as a marketplace is the only exchange that sends price signals (global container freight index) on the market (e.g., on the Baltic exchange) [33]. From Table 1, it is also apparent that these online exchanges have developed an observable strategy of investments [29]. Such investments can be considered as an indicator of (potential increase in) their market share [2]. Market observation in this regard also confirms that the innovation in ICT (information and communication technologies) associated with the rise of exchanges is manifest as a change driver, since today more than hundreds of such exchanges (FTE and DFFs) as start-ups exist worldwide [31]. To our knowledge, these are mainly focused on road, ocean, air, and barge. The multimodal exchange Forto additionally also focuses on rail. The only unrestricted rail exchange we came across closed in 2018. The majority of them operate in the USA and Asia, whereas increasing numbers are observed in Europe, especially dominated by those in Germany [2]. Competition especially in road transport (FTE and DFFs), and ocean and multimodal transport (ocean, air, road) DFFs is increasing [2].

Regarding the business models, partly made visible in Table 1 , the analysis starts with the FTEs that match the definition of online exchanges as discussed earlier in the paper e.g., [12] (notably Freightos, Cargo.one). It is evident that these are profit-based firms. The FTEs focus on fast matching and booking 
online. Further, they provide multiple value added services, including providing visibility of transport operations in real time (e.g., through track and trace, documentation of events etc.). This implies that all data and information exchange between participants is also digitized on the exchange. In contrast, the rise of DFFs has a base in the activities performed by traditional freight forwarders [17]. These DFFs are influencing the dynamics in the market by adding value e.g., in organizing complete transport and offering personalized online support services to complete the transport operations for which the contract was finalized on their exchange [26]. However, in terms of owning transport capacity/assets, the boundary between FTE and DFF remains fuzzy [17]. Some researchers consider DFFs similar to FTEs, assuming that they do not own transport assets/capacities and seek the required support from their partners [26] e.g., currently Sennder and Forto. This contradicts the fact that some DFFs were found that own assets/capacities for supporting urgent demands in transport operations, e.g., Flexport (aircrafts), Cargonexx (trailers), and InstaFreight (trucks) [12,17]. Thus, the boundaries between FTEs and DFFs remain fluid. The argument as to why DFFs, with or without assets, should be considered as a different taxonomy than FTEs was provided in the interviews. It was mentioned by interviewees (i) that ensuring services for completing entire transportation operation as finalized in a contract is a part of the forwarder service (which is considered as a major distinctive characteristic) and (ii) that, due to this, DFFs fully act as freight forwarders following the standard terms and conditions required by the German freight forwarders [34], in line with the German commercial code [35]. This also explains the lack of complete clarity about the DFFs as each DFF may focus on a certain type of freight forwarding business (road DFFs on unique customers in EU, international ones on global shippers, etc.).

The technology innovation is primarily focused on ICT applications. Both the FTEs and DFFs facilitate transactions on the exchange, notably matching, contract finalization and payments for contracts, using innovative matching algorithms, and implementing various ICT applications (e.g., those enabling interfaces between supply and demand side on the exchange; to be discussed in Section 4.2 in relation to the practices). This innovation can be considered as a disruption in the market because it enables exchanges to create a niche market within the highly fragmented industry that is potentially worth billions of Euros [29], effectively answering the demand for low cost services [13,14]. This was also confirmed in interviews. New impacts are created by coordinating activities essential for matching (e.g., the sales process to finalize price and transport services in contracts including clearance, customs clearance, insurance, and brokerage). Moreover, they enable the shifting of traditional interactions taking place between participants (firms) bilaterally, to the exchange, making the exchange the central market place [20-22]. In other words: the existing coordinating processes via fragmented ICT systems, are replaced by a centrally organized and integrated process on the exchange. Through (big data) analytics of real time data, insights are offered regarding possibilities to reduce inefficiencies in transport operations [36].

Platform economy theory argues that often a series of small incremental system changes initially does not appear as a threat to many market actors and is not challenging the dominant institutional framework $[17,24,37]$. Consequently, the majority of shippers, carriers, and freight forwarders seem to react to the emergence of the online exchanges by systematically trying to integrate FTEs and DFFs in their own daily business after gaining some experience with such new exchanges $[2,26,27]$. Apart from shippers, carriers, and freight forwarders, business companies with regional and global supply chains also increasingly participate in the exchange [2,26]. Interviewees confirmed these developments, but nevertheless stressed that the level of adoption varies from low active use of an exchange (e.g., using it as a last resort for organizing empty returns) to some going for full adoption (e.g., for organizing supply chains on the exchange). The views of interviewees converge regarding further potential for disruption through the data and customer centric focus, e.g., differences in opinion exist whether machine learning algorithms can enable understanding relationships between demand and supply side for personalized service, which in turn can be based on neural networks using artificial intelligence for increasing predictive intelligence [38]. 
Finally, such a disruption currently appears to be limited to multimodal (ocean, air, road) and road online exchanges. Those dedicated to rail freight transportation and inland waterways were not found. With the exception of services from Forto, no real coordination and integration of services for rail freight transportation in the EU on exchanges could be observed. However, in interviews, it was considered to be a possible future.

The observed overall structure of different business models in different freight transport modes is presented in Figure 3. Based on this figure, it makes sense (at least for the intended analysis in this paper) to include DFFs in the definition of exchange.

In regard to private online exchanges (Table 2), interviewees stressed that many incumbent freight forwarders (e.g., DBSchenker and DHL) are also offering services as a kind of online exchange [2]. Moreover, these incumbents tend to act as financial investors, investing high sums in unrestricted exchanges, possibly in search for potential and better returns [17,37]. Examples are Maersk's investment in Forto and Lufthansa Cargo's investment in Cargo.one (although here being a minor financial investor). These investments in start-ups that strive for a radical innovation [2,37] seem to indicate a good understanding of the (changing) market's need for multimodality, standardization, and improved matching of demand and supply. Moreover, in line with industrial organization theory, it appears that these incumbent freight forwarders are also responding to the growing level of competition in the market in other ways. Due to capability reasons, such firms also appear to focus on small incremental steps of innovation internally [37,39] in an attempt to tightly link their demand side to them [39]. Examples of such exchanges are Maersk (Twill), Kühne und Nagel (MyKN), VTG (Traigo), DHL (Saloodo!), DBSchenker (Drive4Schenker), and LKW Walter (Loads today). Saloodo! makes an interesting exception as it claims to be both an exchange and a digital freight forwarder.

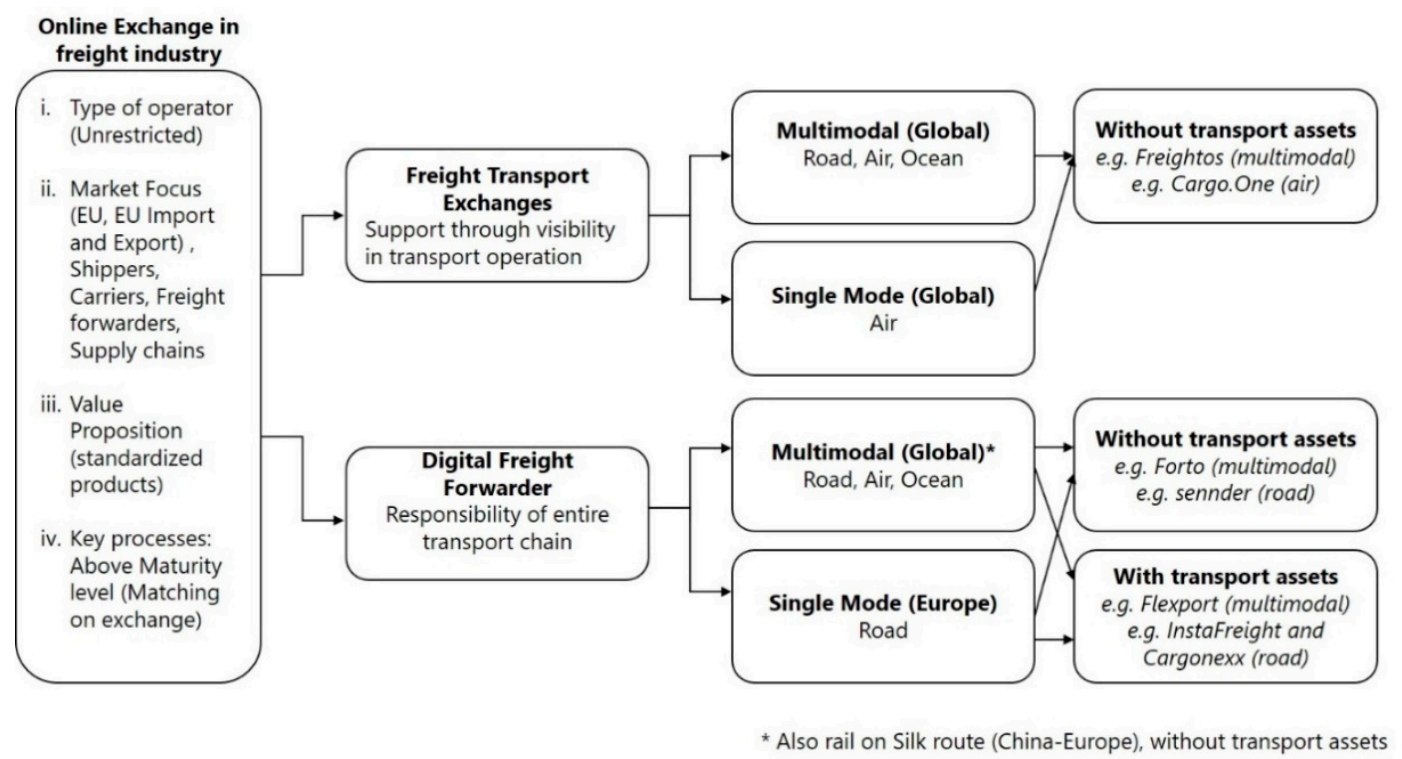

Figure 3. Taxonomy of unrestricted online exchanges in freight industry found in this research. Source: Authors' depiction.

The presented analysis on the freight transport industry shows an increasing number of exchanges that offer matching services to both the supply and demand side of the market, both in single mode transport for road, ocean and air transport, and multimodal transport using these modes. The analysis also revealed that this does not apply to rail and inland waterways within the EU.

With this knowledge, the next step in the analysis is to apply the OEMF for assessing the maturity of practices of exchanges in Table 1. The FTEs and DFFs in Table 2 are not further analyzed, due to a lack of in-depth publicly available data. The focus is on technological innovation to bring the matching of supply and demand of freight transportation services, especially in enhancing multimodal services, 
to a higher level. The analysis enables us to learn lessons for designing multimodal online exchange using rail and road that are effective in improving the share of rail freight in the EU.

\subsection{RQ2: Key Learnings Based on OEMF}

The second research question aims to learn from differences in maturity of unrestricted online exchanges in Table 1. The assessment focusses on the performance of the exchanges' practices, mainly regarding the matching of demand and supply for single mode and especially multimodal services by using technological innovation. First, the market related practices are assessed for their maturity level (low = Level 1, medium = Level 2, high $=$ Level 3), then the operational practices, followed by the technical practices. The practices are mentioned in the OEMF (Figure 1) and their maturity assessment are summarized in Figure 4. The scores are explained as follows.

\begin{tabular}{|c|c|c|c|c|c|c|c|c|c|}
\hline & & & \multicolumn{3}{|c|}{ Multimodal } & Aviation & \multicolumn{3}{|c|}{ Road } \\
\hline & & & $\mathrm{FTE}^{4}$ & DFF $^{5}$ & & FTE & DFF & & DFF $^{7}$ \\
\hline $\begin{array}{l}\text { Key Process } \\
\text { Area }\end{array}$ & Practices & $\mathrm{KPI}^{1}, 2,3$ & Freightos & Flexport & Forto & Cargo.one & sennder & Cargonexx & InstaFreight \\
\hline \multirow{8}{*}{$\begin{array}{l}\text { Market } \\
\text { related } \\
\text { Practices }\end{array}$} & Strategic Management & Proposed benefits & 0 & 0 & 0 & 0 & 0 & 0 & 0 \\
\hline & Product \& Service definition & $\begin{array}{l}\text { Business processes costs as } \\
\text { elements of transaction cost }\end{array}$ & 0 & 0 & 0 & (1) & (1) & (1) & (1) \\
\hline & $\begin{array}{l}\text { Subscription \& product } \\
/ \text { service definition }\end{array}$ & $\begin{array}{l}\text { Frequency of rebates/ } \\
\text { incentives }\end{array}$ & O & 0 & (1) & 0 & (1) & 0 & 0 \\
\hline & $\begin{array}{l}\text { Market \& Stakeholder } \\
\text { management }\end{array}$ & Choice of channels & ○ & 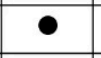 & - & 0 & 0 & $\bullet$ & $\bullet$ \\
\hline & Market rules & $\begin{array}{l}\text { Process and policy } \\
\text { implementation }\end{array}$ & 0 & 0 & 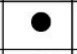 & (1) & (1) & (1) & (1) \\
\hline & Design of Algorithm & $\begin{array}{l}\text { Time to communicate price } \\
\text { signals to market }\end{array}$ & O & (1) & (1) & (1) & (1) & (1) & (1) \\
\hline & $\begin{array}{l}\text { Integration of adjacent } \\
\text { markets }\end{array}$ & Visibility of new markets & ○ & - & - & (1) & 0 & (1) & (1) \\
\hline & Organization development & Choice of technology, talent & O & 운 & 운 & 웅 & D & 1 & 1 \\
\hline \multirow{6}{*}{$\begin{array}{l}\text { Operational } \\
\text { Practices }\end{array}$} & Communication & $\begin{array}{l}\text { Number of channels over all } \\
\text { services and languages }\end{array}$ & (1) & (1) & (1) & (1) & (1) & (1) & (1) \\
\hline & Registration & Average time for certification & (1) & (1) & (1) & (1) & (1) & (1) & (1) \\
\hline & Operationalizing Auctions & $\begin{array}{l}\text { Average time required for a } \\
\text { finalized transaction }\end{array}$ & 0 & (1) & (1) & (1) & (1) & (1) & (1) \\
\hline & Clearing \& Settlements & $\begin{array}{l}\text { Level of process } \\
\text { standardization and } \\
\text { automation }\end{array}$ & (1) & (1) & (1) & (1) & (1) & (1) & (1) \\
\hline & $\begin{array}{l}\text { Data analytics and information } \\
\text { sharing }\end{array}$ & Process maturity & ○ & ○ & ○ & ○ & 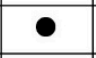 & ○ & ○ \\
\hline & Training \&education & $\begin{array}{l}\text { Number of days/finance spent } \\
\text { in education for each key } \\
\text { employee }\end{array}$ & ○ & ○ & - & $\mathbf{0}$ & (1) & (1) & (1) \\
\hline \multirow{2}{*}{$\begin{array}{l}\text { Technical } \\
\text { Practices }\end{array}$} & Service Organization & Process maturity & (1) & (1) & (1) & (1) & (1) & (1) & (1) \\
\hline & Process Automation & Process maturity & - & $\bullet$ & ○ & (1) & (1) & (1) & (1) \\
\hline \multicolumn{10}{|c|}{ Daturity Level 2 (Curate Level) } \\
\hline
\end{tabular}

Figure 4. Maturity level assessment of practices of the unrestricted exchanges from Table 1. Notes: 1: Including proxy indicators; 2: When available only static figures found, 3: Over all participants over all products and services until specifically mentioned otherwise; 4, 6: Without Transport Asset; 5,

7: With transport assets.

\subsubsection{Market Related Practices}

(a) The "Strategic Management" practice relates to the ability of exchanges in maintaining a process of making continuous choices regarding their strategy and business model (e.g., products, prices, market focus, technology, etc.). These choices align with their economic, social, and environmental goals towards optimizing benefits offered to participants on both sides. The performance of this practice can be measured by the average improvement of the benefit that each participant on the exchange receives through technological innovation, over all products and services since the last period, and evidently in compliance to the regulatory requirements.

The analysis summarized in Table 3 shows that all online multimodal and single mode transport exchanges (FTEs and DFFs) appear to set objectives aligned to benefits of markets they focus on, 
through matching and finalizing the entire chain of transport services. Benefits can relate to economic, social, and environmental welfare. Data for such benefits were found with respect to process efficiency (interpreted as economic benefits) and other economic gains. The social benefits, especially in road exchanges relates to reducing empty returns. Few exchanges in addition also explicitly set goals for environmental benefits (e.g., Sennder). Data regarding proposed benefits can be found on exchange websites, but unlike for other network industries (e.g., power exchanges in the energy industry) these are not publicly available over regular periods to prove the claimed benefits.

Table 3. Benefits and aims of the selected online exchanges.

\begin{tabular}{cccc}
\hline Exchange/Mode & Benefit Type & Proposed Benefit & Mission, Vision \\
\hline $\begin{array}{c}\text { Freightos [40] } \\
\text { Multimodal, FTE }\end{array}$ & Economic ${ }^{1}$ & $\begin{array}{c}\text { Deliver immediate } \\
\text { freight prices, easy } \\
\text { switching between } \\
\text { logistics providers }\end{array}$ & $\begin{array}{c}\text { Frictionless trade: SaaS-Enabled Marketplace } \\
\text { model, helping leading logistics automate } \\
\text { their internal freight rate management, } \\
\text { pricing/routing, and business intelligence. } \\
\text { Using same technology for the supply side }\end{array}$ \\
\hline $\begin{array}{c}\text { Flexport [41] } \\
\text { Multimodal, DFF }\end{array}$ & Economic ${ }^{1}$ & $\begin{array}{c}\text { 2.5 h effort per week for } \\
\text { each shipment }\end{array}$ & $\begin{array}{c}\text { The operating system for global trade. } \\
\text { One platform to manage everything }\end{array}$ \\
\hline $\begin{array}{c}\text { Forto [42] } \\
\text { Multimodal, DFF }\end{array}$ & Economic & 35,000 Euro/year ${ }^{2}$ & $\begin{array}{c}\text { We harmonize technology and logistical } \\
\text { know-how in a powerful way. }\end{array}$ \\
\hline $\begin{array}{c}\text { Cargo.one [43] } \\
\text { Single mode, FTE, Air }\end{array}$ & Economic ${ }^{1}$ & $\begin{array}{c}\text { 39 s booking process } \\
\text { time as time to customers }\end{array}$ & $\begin{array}{c}\text { To change the air freight industry } \\
\text { Sennder [44] }\end{array}$ \\
$\begin{array}{c}\text { Single Mode, DFF, Road } \\
\text { Cargonexx [45] }\end{array}$ & Social, Economic & $\begin{array}{c}\text { Reduce 20\% empty Kms } \\
\text { 2019: Total 185,000 Kms }\end{array}$ & $\begin{array}{c}\text { Moving trucks (full truck load) with the } \\
\text { power of data and automation to unlock } \\
\text { endless capacity and unparalleled quality }\end{array}$ \\
\hline $\begin{array}{c}\text { Single Mode, DFF, Road } \\
\text { InstaFreight [46] }\end{array}$ & Economic ${ }^{1}$ & $\begin{array}{c}\text { Weekly payments for } \\
\text { carriers ensured }\end{array}$ & $\begin{array}{c}\text { Support of European truck logistics in } \\
\text { digitalization process to make the world a } \\
\text { little bit better. We stand for state-of-the-art } \\
\text { technologies, networking, } \\
\text { fairness, transparency }\end{array}$ \\
\hline Single Mode, DFF, Road & Economic ${ }^{3}$ & $\begin{array}{c}\text { 20-40 min saved per } \\
\text { carrier and transport. } \\
\text { Cost (shipper) }\end{array}$ & $\begin{array}{c}\text { We transport logistics into the digital age and } \\
\text { become the leading provider for road freight } \\
\text { in Europe }\end{array}$ \\
\hline
\end{tabular}

Source: Data from websites of respective exchanges. Notes: ${ }^{1}$ : Process efficiency, ${ }^{2}$ : by switching from traditional forwarder to Forto, ${ }^{3}$ : Financial and process efficiency.

Based on the information on their websites [40-46], a systematic process of steering on strategic choices appears to exist and is reflected in their current goals. To be more precise:

- Freightos aims at global companies and small businesses since "online sales and automation for the trillion-dollar freight industry is non existent";

- Flexport aims to be the only one that "connects all the parties in global trade-importers, exporters, trucking companies, ocean carriers, airlines, customs agencies, port terminals-through a single, secure cloud-based platform";

- Forto aims at "gaining control over the entire supply chain";

- Cargo.One offers a process of "dynamic pricing with a click of button" in air transport;

- Sennder aims to "fast forward road logistics into digitalization" e.g., "by offering shippers access to our connected fleet";

- Cargonexx aims at "connecting all market players, to reduce inefficiencies and empty runs through technology thus saving time and money";

- InstaFreight aims for reliability, quality, efficiency (e.g., "Attractive prices due to automated processes") and transparency.

A direct setting of environmental goals e.g., reducing $\mathrm{CO}_{2}$ emissions could not be found and appears to be a by-product e.g., from facilitating a better utilization of capacity (Forto, Sennder, Cargonexx). It appears that such a goal is dependent on the requirements of shippers. An example 
is IKEA, which has set goals on reduction of its carbon footprint by aiming at a model shift to reduce congestion, improve road safety, and to improve the work-life balance of truck drivers [47]. Nevertheless, some focus in favor of environmental goals could be found, e.g., Flexport recommends a donation per ton of carbon emissions to customers, which is then invested in sustainable projects to offset the emission. Carbon emission calculators offer the ability to search for environmentally friendly ways for transporting [48]. Regulatory requirements in international air and ocean transport are strictly defined. Strategic goals are thus currently primarily aligned to optimizing benefits for customers and compliance to regulatory requirements, and secondarily and in only a few cases to environmental goals.

Thus, with regard to strategic management practices, multimodal FTEs, multimodal DFFs, single mode FTE (for aviation), and DFFs (for road) are all at maturity Level 3.

(b) The "Product and service design" practice relates to the strategic decisions of exchanges to continually increase their responsiveness towards market requirements. This implies organizing product and service specifications as the basis for value adding interactions to increasingly facilitate the matching between supply and demand, notably with regard to multimodal transport services. The practice performance can be measured by the average reduction in transaction costs per participant over all products and services since the last period.

Table 4 provides an overview of all products and services of the online exchanges. Public data on this indicator over a time period could not be found. Therefore, the analysis relies on the information regarding the underlying causes for occurrence of such costs as proxy indicator. These often relate to business processes, e.g., search costs for finding the right carrier or shipper and other aspects of services [49]. Details on such causes could be found on exchange websites and are mentioned in Table 4 under the heading of transaction costs.

Table 4. Exchange products and services.

\begin{tabular}{|c|c|c|}
\hline Exchange & $\begin{array}{l}\text { Transaction Costs, } \\
\text { Average Reduction }{ }^{1}\end{array}$ & Product and Service Description \\
\hline Freightos & 3 days manual search $\operatorname{cost}^{2}$ & $\begin{array}{l}\text { Small business importers: Instant comparison for air, ocean, and trucking } \\
\text { freight quotes, balance of price and transit time from reliable forwarders } \\
\text { and carriers } \\
\text { FBA: Visibility and control across shipment-palletization in container and } \\
\text { labelling using an app-like solution. Customer service, document } \\
\text { management for shipment } \\
\text { Individual supply chain: instant freight rate index for market comparison is } \\
\text { made available }\end{array}$ \\
\hline Flexport & $\begin{array}{l}35 \% \text { shipment cost through } \\
\text { ocean match }{ }^{3} \\
1-2 \text { months instead of 3-6 } \\
\text { for insurance claims }\end{array}$ & $\begin{array}{l}\text { Logistics: FCL, LCL, Ocean Match (best match to optimize container } \\
\text { capacity) and Track and Trace. Air service to individual supply chain } \\
\text { providers, fast transit services. Road: Integrated in the supply chain service } \\
\text { Trade and financial services: Customer brokerage, trade related compliance. } \\
\text { Supply chain services: Carbon neutral transport on demand. API: Data } \\
\text { integration with the exchange }\end{array}$ \\
\hline Forto & $\begin{array}{c}30 \% \text { of administrative time, } \\
15 \% \text { cost of the total } \\
\text { costs/transport }\end{array}$ & $\begin{array}{l}\text { Logistics solutions: Ocean (Long term contracts, spot via Maersk), } \\
\text { Air (Spot contracts) }{ }^{5} \text {, Multimodal (Using FCL and LCL). Rail: Between } \\
\text { Europe and Asia }{ }^{6} \\
\text { Supply Chain: Order Management: } 24 \text { X7 operational status, data analysis. } \\
\text { Individual services: Clearance, customs, Container consolidation, } \\
\text { Warehousing, FBA. E-commerce (Order rates, tracking, order management } \\
\text { etc.). Integration of data through APIs (application interfaces) }\end{array}$ \\
\hline Cargo.one & Booking time down to $39 \mathrm{~s}$ & $\begin{array}{l}\text { Booking for freight forwarders in spot market }{ }^{7} \text { : View, compare, and book } \\
\text { quotes from } 1 \mathrm{~kg} \text { to } 10 \text { tons. Tracking is included. } \\
\text { Selling for Carriers: Selling capacity, overview and managing revenue by } \\
\text { dynamically changing rates } \\
\text { Data services: Market data access on product, price, and revenues }\end{array}$ \\
\hline
\end{tabular}


Table 4. Cont.

\begin{tabular}{|c|c|c|}
\hline Exchange & $\begin{array}{l}\text { Transaction Costs, } \\
\text { Average Reduction } 1\end{array}$ & Product and Service Description \\
\hline Sennder & $\begin{array}{c}\text { Truck available for express } \\
\text { deliveries now within } \\
180 \text { min } \\
\text { Payment in } 3 \text { days } \\
\text { for carriers }\end{array}$ & $\begin{array}{l}\text { Specialized transport for Shippers: Refrigerated goods for supply chains } \\
\text { (-30 deg C to }+30 \text { deg C) in Europe. } \\
\text { Express deliveries: Pallets and FTL. Special loads (custom size transport } \\
\text { with special equipment). Consumer goods industries with last minute } \\
\text { changes. E-commerce for specialized supply chain solutions. Same day } \\
\text { logistics (estimated time of arrival notified) } \\
\text { Carriers services: Automated shipment allocation, less empty Kms, planned } \\
\text { tours, fast payments. Insurance and maintenance services through partners }\end{array}$ \\
\hline Cargonexx & $\begin{array}{l}\text { Now weekly payment } \\
\text { to carriers }\end{array}$ & $\begin{array}{l}\text { Shipper and carrier services: Tender and spot search with trusted } \\
\text { participants, with individual support. } \\
\text { Performance monitoring. Capacity focus on } 40 / 12 / 7.5 \text { ton capacity }\end{array}$ \\
\hline InstaFreight & $\begin{array}{l}\text { Delay (shippers). Now } \\
98.4 \% \text { on-time delivery) } \\
20-40 \text { min time for } \\
\text { documents (carriers) }\end{array}$ & $\begin{array}{l}\text { Shipper and carrier services: B2B freight forwarder. Complete digitization } \\
\text { of pricing, booking, track and trace, and document handling }\end{array}$ \\
\hline
\end{tabular}

Source: Data from websites of included exchanges. Notes: ${ }^{1}$ : As element of business process, ${ }^{2}$ : Based on customer experience, ${ }^{3}$ : Saved offset is contributed to a project on reducing carbon emissions at carbonfund.org, ${ }^{4}$ : For those claims not organized by Flexport, ${ }^{5}$ : IATA license to access partner network, ${ }^{6}$ : No market information, ${ }^{7}$ : As per IATA regulations. Abbreviations: FBA: Fulfilment by Amazon, API: Application interface.

The analysis shows that all exchanges are B2B online exchanges. Further, careful decisions on market focus (geographic areas, mode, industry focus, demand or supply side, horizontal or vertical, etc.) and products/services (logistics services that are mode-based, transport commodity and supply chain services) with sufficient product differentiation (e.g., full container load, less than a container load, pallets, or specialized transports), have been made. Multimodal exchanges also provide individual transport mode services based on customer requirements. Regarding modes, Forto was found to be the only exchange that communicates the use of rail. Freightos organizes ocean and rail transport between China and US but not in the EU.

Digitalized value-added services for quantitatively optimizing matching, and consequently also customer efficiency, are more visible in the multimodal exchanges and aviation exchanges, possibly due to higher standardization in containers, pallets, and box sizes. These become notably manifest in additional services (customers, brokerages etc.), revenue management (Cargo.one), and most in the data integration for managing the participants' complete business. Road DFFs appear to fill in their value added services in terms of document management, insurances, and, e.g., offering special equipment. It appears that, for spot requests and for complete shipping throughout the whole supply chain over long term, the exchanges aim at finding the price dynamically for the demand side. Only Cargonexx explicitly used the word "Tender" in its products and services. In terms of performance, transaction costs improvement appears to focus on search cost, booking cost, shipment cost (partly search cost), post shipment costs, and administrative costs (payment, insurances, documentation). Thus, it appears that benefits including reduction in average transaction cost by using the exchanges outweigh the switching costs and transaction fee that is charged to the participants.

Given these observations, all multimodal online exchanges are evaluated at maturity Level 3, basically since processes appear to be monitored, controlled, and optimized continuously over multiple products (transport modes) for maximizing liquidity and optimizing capacity on the exchange. The same appears to be the case for the aviation FTE but it does not offer multimodal services. Finally, especially the data integration services in road DFFs currently do not appear to be offered at the same extent as the multimodal ones. Therefore, the single mode FTE (for aviation) and DFFs (for road) are assessed at maturity Level 2.

(c) "Subscription and product/service pricing" practice relates to decisions on pricing for the products and services via subscription to the exchange, in order to balance the level of services offered (for which participants would be ready to pay) with the demand for the service. The performance of 
the practice can be measured by change in frequency of rebates and incentives to the participants for subscription. Rebates and incentives are not offered when balance is achieved.

None of the exchange websites appear to offer any rebates, which implies that apparently sufficient liquidity, trust of participants, and consumption of services on both sides exists. Most exchanges appear to continuously optimize their matching quality and training of the matching algorithms. The quality is improved by mapping customer requirements, e.g., deduced from their subscription to the exchange. The data training is supported by, e.g., machine learning. Multimodal FTE Freightos asks for the number of shipments made annually, the type of freight (e.g., box, crates, pallets), the origins and destinations for transport, and other services (e.g., customs).

Multimodal DFFs, such as Forto, take the potential participant through a series of multiple-choice questions regarding the benefits they are seeking for, transportation modes used, source and destinations of shipments, number of containers shipped, etc. It shows their ability of monitoring the process of understanding participant requirements that is needed for balancing consumption. Such an observation is not visible for Flexport and the aviation FTE. Road DFFs show varying levels of practices. Sennder asks questions on language preferences, loading/unloading areas and whether the participant is a freight forwarder. For others (InstaFreight, Cargonexx) this step is not visible. Finally, the exchanges appear to charge per transaction, and no subscription costs (e.g., monthly, annually) for each product could be found on the exchanges. Finally, Freightos differentiates the price for its services, e.g., a percentage of the finalized transaction of participants and a fixed fee for adhoc (potential) participants for restricted services (for bilateral contracts) [50]. All other exchanges appear to charge per transaction [2,26].

Therefore, the multimodal FTE is evaluated at maturity Level 3, whereas some multimodal DFFs are at Level 2 but capable of moving to Level 3 (note that Flexport is assessed at Level 1). The aviation FTE appears to be at Level 1, and road DFFs show varying levels, e.g., Sennder at Level 2 and others Level 1.

(d) "Market and stakeholder management" practice relates to the process of strategic decision making for engaging with different stakeholders (notably the participants, partners, and service suppliers) before, during and after the matching process. The practice performance can be measured by investment in communication through different channels. Information on investments was not found. Alternatively, information on the exchanges' websites on the choice of channels used for communication might be used as a proxy.

All exchanges actively use different channels to engage and interact with stakeholders, especially the participants, at different points of time. These channels include personal meetings, events, chats, conferences, trainings, etc. Technological innovations for matching and improvement of transport services, facilitates decision making on (new) partnerships (that are also digitally interfaced) required for achieving and optimizing customer benefits. They have organized for track and trace services. In terms of business model, regarding customer support services, they either choose to communicate e.g., during transport operation themselves (e.g., Forto) or choose to outsource this to their partners (e.g., Flexport). What is common is that they all have made the choice to support participants.

Concluding, the maturity level of all selected exchanges is assessed to be at Level 3.

(e) Market rules are based on strategic decisions regarding improving (i) matching quality and balancing of the average consumption of products and services on both sides of the exchange, and (ii) the governance to ensure no harm to participants or the exchange occurs. The practice performance can therefore be measured by the increase in number of transactions on both sides and the transparency on frauds as well as complaints (indirectly). Public data on such details were not found, but the rules are mentioned in terms and conditions e.g., circumventing the exchange after initial contracts on the exchange, using contract details outside the exchange, and audits by a third party regarding the compliance to regulatory procedures and exchange rules. On the other side, exchanges also communicate rules that they themselves must comply with (i.e., self-regulation).

The multimodal FTE Freightos' way of working is in line with the maturity growth theory. It organizes rules in its generic services agreement form, that is supportive in later standardizing, 
monitoring, and optimizing exchange operations. This implies e.g., the agreements are applied to all the participants that use Freightos [51]. It enables Freightos to continuously audit and enforce measures to curb non-conformances in its process and policy implementation in an efficient manner. Multimodal DFFs define such rules in "terms of use" or "terms and condition" and "privacy policy". E.g., Flexport [52] requires participants to commit themselves to confidentiality of all information involved in the supply chain, including the ports, which is not limited to price information only. Forto mentions the compliance for GDPR regulations (EU's General Data Protection Regulation, DSGVO in German) [53] and other international rules to be followed while transferring data to its service provider (notably Amazon Web Services). Further, the exchange also guarantees the participant's rights regarding data provision, data use, and the right to object. It shows that standards and policies on behavior are set, but standardization in the industry is not yet visible. The aviation FTE in this respect appears to be similar to the multimodal DFFs. Road DFFs' market rules currently vary from each other. E.g. InstaFreight and Cargonexx define standards and policies for the processes on the exchange e.g., from registration to payment of services, insurance etc. [54,55]. Sennder defines standards along the transport process that includes e.g., stillage, demurrage etc. [56]. Sennder discusses aspects of physical delivery.

The conclusion is that the maturity of the multimodal FTE is assessed to be at Level 3, and all others at Level 2.

(f) The "Design of algorithms" practice relates to the exchange's process of making strategic choices regarding the design of ICT-based algorithms for the matching of supply and demand. The performance of the practice can be measured by the average time required to communicate a price signal to the market. Such a regular communication builds trust and facilitates market competition [57].

Exchanges on their websites stress that matching and price discovery for the right transport partner can be simplified, despite complexity in transport business. Moreover, understanding requirements of participants on both sides is key. Multimodal FTE Freightos is the only exchange communicating a price signal publicly (Freightos Baltic Index: Global Container Freight Index, on a daily and weekly basis). This has opened gates for the use of freight derivatives by forwarders and carriers to hedge underlying contracts or spot market purchases [58]. Further, Freightos offers the demand side a possibility of dynamic change in selection criteria for services, which the matching algorithm then automatically takes into consideration while performing the matching.

The multimodal DFFs currently appear to be focused on innovating, automating, and optimizing their algorithms to generate a price for various offers (multimodal and single mode). The demand side can choose to select (notably multimodal transport) offers manually. A price signal is not yet communicated publicly to the market. Other auctions, mainly the reverse Dutch auctions (implying that the demand side decides) and English auctions (implying that the supply side decides) can be observed.

Aviation FTE Cargo.one, as mentioned before, aims to achieve "more transparency to the overall market and enable freight forwarders to book freight on a specific flight at a specific dynamic price with a simple click of a button". This is indicative of price discovery. Cargo.one also presents an overview of offers from the supply side to let the demand side to choose from. Further, it offers carriers a revenue management service for their customers. The service includes offers based on the dynamic market price information from Cargo.one in real-time (adjusted rates based on time to departure, capacity fill rates etc.). Sennder and InstaFreight perform automatic matching but without communicating price signals to the market. In all road DFFs, a shipper can demand a transport service within a certain price range. The matching algorithm is designed to allocate a carrier to the shipper based on this detail; the carriers, however, remain anonymous to the shippers until completion of the matching. This underlines that trust in the matching algorithm to discover the price does exist.

Therefore, all exchanges focus on price discovery. The multimodal FTE Freightos, being the only one communicating a price index in the market, is evaluated at maturity Level 3. Multimodal DFFs (Flexport, Forto) and the aviation FTE (Cargo.one) offer functionalities based on price insights to their 
participants but do not send a public market signal yet, and are therefore evaluated at Level 2 but being capable of moving to Level 3. Road DFFs are similarly assessed at Level 2 and capable of moving to Level 3.

(g) The "Integration of adjacent markets" practice is about seeking higher benefits for participants of the exchange by understanding their challenges outside the exchange and bringing new participants on the exchange. Its performance can be measured in terms of the total investment in new projects or the increase in the number of participants. Standardized public data was not found; however, information on new markets e.g., in literature, market reports and new funding can be treated as indicators of the level of maturity of this practice.

The multimodal FTE and DFFs have clearly broadened their orientation to adjacent markets continuously focusing on participant requirements, e.g., by offering services to Amazon. For example, FBA services (Fulfilment By Amazon) are services designed to support the prime users of Amazon [59-61]. Amazon offers these services to sellers for storing their products in the fulfilment (distribution) centers, then organize delivery to the prime customer of the sellers. This includes picking, packing, shipping, and providing customer services on behalf of the sellers. The key to this success appears to be on the ability to provide services to customers by organizing visibility and information in the logistic processes through technological innovation such as artificial intelligence, machine learning and digital document management [62]. Further, Freightos with its new services "Freightos data" has entered into a new market of providing data to e.g., financial institutions like Reuters, Bloomberg etc. It also made the strategic choice of acquiring and integrating the air freight bazaar India exchange to expand Freightos' access in the aviation market. The participants of the acquired exchange can also access the Webcargo exchange for dynamic pricing [63]. Further, Forto also integrated Maersk's spot exchange in its ocean freight services [64]. Overall, the process for identifying, developing, and continuously optimizing products and services for adjacent markets on the exchange appears to exist.

The aviation FTE and the road DFFs show sufficient liquidity on their exchange but are focused on learning new requirements from the (changing) market. In aviation, Cargo.one is clearly focused on becoming global as more and more participants (carriers, and individual forwarders as well as forwarding companies) on both sides are joining the FTE. A common regulation (notably IATA) apparently facilitates this process. In road DFFs, Sennder joined Everoad (another DFF), that is active in Europe (6500 carriers), calculating and displaying the cost of loads in real-time [65]. Such a process of moving to adjacent markets was not found for InstaFreight and Cargonexx.

The conclusion is that the maturity level of these multimodal exchanges (FTE and DFFs) and road DFF Sennder for this practice is assessed at maturity Level 3, whereas the aviation FTE and other road DFFs are assessed at Level 2.

(h) The "Organization development" practice relates to the process of articulating intellectual rights (patents for product design, computing models), implementing technical innovations (capturing and analyzing data, new product designs) and creating the necessary human resources for developing algorithms, organizing the best customer service, etc. The performance of this practice can be measured e.g., by the total budget for funding for new technologies and resource acquisition. Data regarding patents can be deduced from various market research databased. As a proxy indicator, the choice of technology and talent has been used for maturity level assessment.

The choice of technology in exchanges includes SaaS, Google Analytics, Cloud computing, Kubernetes ecosystem, artificial intelligence, and machine learning tools, which offer powerful computing abilities [2,26-28]. It appears that this choice relates to $80 \%$ of the applications being chosen as 'off the shelf' solutions. Hence, $20 \%$ of the applications need to be customized for the business being focused on [66]. More importantly, this choice facilitates ease of integrating all partners' and participants' ICT systems without the need for programming for each interface individually. For this, the exchanges choose for offering a development portal for APIs (application interface) [67]. In this way, large amounts of real time data between the exchange and its participants as well as 
partners can be transferred. This suggests a high maturity to share software codes in order to enable interfacing with external systems. All multimodal FTEs and DFFs offer additional APIs to exchange data with participants regarding e.g., freight estimates (Freightos), real time notifications (Forto), booking, tracking, and invoicing (Flexport). The aviation FTE Cargo.one presents its stack showing details on frontend, backend, and infrastructure being used for applying technical innovation in the exchange functions. Such information for road DFFs was not found.

Regarding organizational forms, especially the multimodal exchanges organize cross-functional team of experts to support their participants e.g., in tracking the operations until finalization. The common focus of all exchanges with respect to talent recruitment currently appears to focus on sales, product design, software engineering, customer experience, and finance. Road DFFs appear to search for talent in machine learning and artificial intelligence. No mentioning of expertise on APIs could be found. Apparently, interfacing with participants and partner ICT systems is not yet the key focus.

Concluding, the multimodal FTE and DFFs, and the aviation FTE are evaluated at Level 3, whereas road DFFs are at Level 2 but ready to move to Level 3.

\subsubsection{Operational Practices}

Operational practices are related to implementing the strategic choices made in market related practices. They relate to coordinating different activities to implement the operational processes of the exchanges. The performance relates to reaching a higher level of standardization of processes and polices through which analytical optimization on the exchange goals is enabled. Such goals are communicated internally in the exchange and externally to the participants and other stakeholders.

(a) The "Communication" practice relates to the operationalization of choices on how to interact with stakeholders, especially participants (existing and potential). All DFFs and FTEs find it important to make a personal contact with stakeholders, especially with the participants, and organize customer events. This can also be observed in interviews. Other channels of interaction with participants (current and potential) as well as stakeholders (e.g., general public) are mentioned in Table 5. The performance of this practice can be measured by the number of channels used for communicating for all services and all languages over the last period.

Table 5. Communication channels of exchanges with stakeholders (as on 11.05.2020).

\begin{tabular}{clccc}
\hline Exchange & Digital Mix ${ }^{\mathbf{1 , 2 , 3}}$ & Chatbot & Events $^{\mathbf{3}}$ & Languages $^{\mathbf{4}}$ \\
\hline Freightos & YouTube (up to 1000) & Yes & Yes & Up to 3 \\
Flexport & YouTube (up to 1000) & Yes & Yes & Up to 3 \\
Forto & YouTube (up to 500) & & Yes & Up to 3 \\
Cargo.one & YouTube (up to 50) & Yes & Yes & Up to 3 \\
Sennder & YouTube (up to 50) & & n.a. & Up to 5 \\
Cargonexx & YouTube (up to 50) & & n.a. & over 5 \\
InstaFreight & YouTube (up to 50) & & n.a. & Up to 3 \\
\hline
\end{tabular}

Source: Data from websites of included exchanges. Notes: ${ }^{1}$ : Social Media (Facebook, Twitter, YouTube) and Newsletter, Blogs, Webinars, Business news, ${ }^{2}$ : Range of viewers, ${ }^{3}$ : Customer events ${ }^{4}$ : Languages supported.

All exchanges facilitate their participants in selecting preferences on how they want to be communicated with (language, geographical specifications, timings, topics etc.). In social media, Facebook and twitter are common but Chatbot does not appear to be as common as it is generally found on digital platforms. Youtube is more popular in multimodal exchanges, and webinars on blogs appear to be common for all exchanges. Finally, multimodal exchanges and aviation FTE stand out in organizing events like workshops, conferences etc. for customers but also offer market updates as value addition for customers. In terms of languages of websites, the multimodal exchanges appear to often use English and those on the road offer further languages of the market they cover. 
In terms of maturity assessment, the process and policies for communication appear to be defined and somewhat standardized over exchanges. Optimizing such activities towards customer efficiency becomes visible, e.g., in webinars and news on the exchanges' websites, but not on the other channels. Therefore, this practice is assessed at Level 2 for all the exchanges.

(b) "Registration" serves as the entry point, first by allowing the interested participant to register the interest in joining the exchange, and secondly, the exchange checking credentials before allowing to join the exchange. Faster matching is enabled when only serious participants are allowed to register and participate on both sides. The practice can be measured in terms of relative improvement in average time required to certify a participant for registration on the exchange since the last period.

Multimodal FTE Freightos offer a simple first step including use of social media for a login that facilitates basic data collection on the participant. The basis for the second step is clearly mentioned on its "Master service agreement" regarding registration, subscription, etc. Multimodal DFFs have similar practices, with their details being mentioned in the "terms and conditions". The time required for registration was neither found for multimodal online exchanges. Aviation FTE Cargo.One uses a CRM software services (Salesforce) for registration and is currently perceived as basic, asking for the e-mail address for starting (3 min for registration, 100\% free). Road DFFs specifically ask for conformation during creating a login, that the interested participants is a "business customer" as defined in terms and conditions. Time required for confirmation was not available here either. Finally, exchanges that have integrated the services of other exchanges with their own services (e.g., Freightos, Forto, and Sennder), appear to offer access to the participants of both exchanges without the need for a new registration. This suggests operational efficiency on the exchange.

We evaluate the maturity of all exchanges at Level 2 as standards and policies exist for registration. The practice can be better monitored and controlled if goals are set for the time required for a safe registration.

(c) The "operationalizing auctions" practice relates to clearly defining and implementing standards for matching set in the practice "design of algorithms". Transparency relates to informing on the status of process execution (e.g., time and possible complaints). The performance of this practice can be evaluated by the average time required for an automated transaction (from start to finish).

Multimodal FTEs and DFFs appear to implement machine learning in implementing the matching algorithms in such a way that changes in participant's preferences do not affect the algorithms. This implies that matching is increasingly based on flexibility and continuous learning. Further, the demand side often receives instant multimodal offers, e.g. by mail. The predicted prices for these offers (based on particular days for a certain period) are displayed. An offer is locked for the demand side when it accepts a particular transport service offer from the supply side. As mentioned earlier, Freightos creates a global container index out of these auctions, which is communicated in $48 \mathrm{~h}$ on the Freightos Baltic index and can be used for contract negotiations and derivates in the market. This illustrates that goals are possibly set regarding closure time for transactions and price communication. A differentiated approach of assessment must be taken for organizing rail transport (e.g., Forto) that still requires operational issues to be handled and hence possibly requires a longer transaction closure time. Aviation FTE Cargo.one aims to make instant offers based on the preference of the demand side participant. Road DFFs (Sennder, InstaFreight) differ in that the carriers remain anonymous in the matching process and the algorithm automatically allocates these to the shippers. This implies that no manual intervention in the matching process takes place, which seems to be acceptable to the participants. Cargonexx allows the shippers to choose their offers, but a market price communication does not take place.

Concluding, the multimodal FTE is evaluated at Level 3 and all other exchanges at Level 2.

(d) The "Clearing and settlements" practice relates to the finalization of a transaction (post matching) for which the promised service was provided and payment to the supplier(s) and exchange must be completed. The practice can be measured by the reduction in average number of delays and failures to pay or deliver an obligation since the last period; however, data in this regard 
was not found. The assessment is done on the basis of level of standardization and automation of the practice, and further whether optimization for customer efficiency is achieved through specific activities.

Multimodal FTE Freightos offers multiples options for payment, acting as a collecting agent for the supply and demand side. Further, a payment directly to the supply side without Freightos being involved is also possible. It offers a detailed guide for participants on requirements that participants should specify for matching, e.g., regarding transportation services and payment conditions. Multimodal DFF Flexport has outsourced the clearing and settlement activities to a third party, (Plaid) which is responsible for collecting payments, processing payments, and tracking the creditworthiness for participants. Such information is not available for Forto. Aviation FTE Cargo.one is highly standardized due to the use of IATA's (international air transport association) CASS (Cargo Account settlement system), which is used by the majority of carriers worldwide. This includes the payment, creditworthiness checks, annual fees for joining the exchange. Road DFFs follow bank transfers or direct payment. Further, they have third party organizations that regularly check the creditworthiness of the participants. The number of days in which a credit note will be paid or the shipper has to pay is usually mentioned.

Based on this information, the maturity level of all exchanges is assessed at Level 2.

(e) The "Data analytics and information sharing" practice relates to the need for optimizing key processes and supporting customers in optimizing their processes too. Such transparent communication, e.g., of the results of transactions to the participants and markets in a consistent, standardized, and automated fashion (using different channels), increases participants' trust in the exchange. The performance can be measured by the average progress of implementation of data analytics requests. Since this information is not publicly available, the process maturity perceived in implementation is used as an assessment criteria.

The value proposition for multimodal online exchanges comes from regularly making data standardized and visible to their participants and markets. This data refers to e.g., every possible supply chain and possible bottlenecks. As a result, dashboards are provided to participants for continuous tracking of shipments. The aviation FTE offers insights to customers for revenue management. Road DFFs are focused on data analytics for visibility in transport operations. Thus, handling large data and analyzing them (e.g., with big data analytics) seems to be made possible. The exchanges appear to have a standardized process in this regard which can be continuously optimized for customer efficiency. Thus, the maturity level of all exchanges is assessed at Level 3.

(f) The "Training and education" practice relates to exchanges operationalizing their strategic decisions on organizational development (including investment in training and education) to align their responsiveness towards markets. This includes, e.g., training employees to cope with the complexities of matching. The practice can be measured by the average number of days spent in education for key employees since the last period based on planned initiatives. The collected information is presented in Table 6.

The multimodal FTE Freightos appears to have set goals on employee trainings for understanding customer requirements. Further goals relate to knowledge sharing towards potential participants and existing participants (e.g., market updates, webinars, papers and community interaction on Facebook). The multimodal DFFs Flexport and Forto have similar practices as Freightos. In case of the aviation FTE (cargo.one) neither information was found. Road DFFs also focus and budget their training; e.g., Sennder informs on the number of days set for training. Knowledge sharing does not appear to be the focus. The analyses of community interactions (usually with participants) on Facebook shows for the multimodal FTE and DFFs a higher level of participation than for the aviation FTE and road DFFs. Consequently, participants of the exchange act as a free resource of the exchange.

Thus, the maturity of multimodal FTE and multimodal DFFs are evaluated at Level 3, the aviation FTE at Level 1, and of the road DFFs at Level 2. 
Table 6. Training and Education practice on exchanges (as on 11.05.2020).

\begin{tabular}{cccc}
\hline Exchange & Training and Education $^{\mathbf{1}}$ & For customers and Market $^{2}$ & User Community $^{3}$ \\
\hline Freightos & $\begin{array}{c}500 \text { USD and } \\
\text { ongoing training }\end{array}$ & $\begin{array}{c}\text { Freight education and } \\
\text { logistics Tech \& Data }\end{array}$ & Over 2500 users \\
\hline Flexport & 1 week $^{5}$ & Whitepapers, tariff insider & Over 2500 users \\
\hline Forto & 600 Euros & Whitepapers & Over 2500 users \\
\hline Cargo.one & n.a. & n.a. & Up to 50 users \\
\hline sennder & 2 weeks ${ }^{5}$ & n.a. & Up to 500 users \\
\hline Cargonexx & Individual training & n.a. & Up to 500 users \\
\hline InstaFreight & Start training & n.a. & Up to 500 users \\
\hline
\end{tabular}

Source: Data websites of included exchanges. Notes: ${ }^{1}$ : Average number of days or finances for education/ employee per year, ${ }^{2}$ : Other than market updates, webinars, and blog), ${ }^{3}$ : (on Facebook), ${ }^{4}$ : for demand and supply side, including price index as well as software developers, ${ }^{5}$ : Exchange's own academy.

\subsubsection{Technical Practices}

(a) The "Service Organization" practice relates to ensuring support to participants (new and existing) in their use of products and services they subscribe to on the exchanges. Support needs can, e.g., relate to adapting the participant's business model. The performance of this practice can be measured by the percentage of issues closed over total issues since the last period. Since no data was publicly found, the process of implementing the service organization was used as an assessment criteria.

Multimodal FTE (Freightos), based on a standardized master service agreement, offers credits depending on the uptime services that were promised and could not be managed. This implies there is a continuous effort to optimize services that are automated. Multimodal DFFs show varying levels of performance. They are more oriented towards continuous support in transport services; e.g., Flexport offers their participants a cross functional team of logistics experts (called SQUAD) for handling issues arising during their transport operations finalized on the exchange. As a result, $84 \%$ of Flexport participants consider these teams as their extended logistics team [68]. Forto mentions being a technology service offering full service model in logistics services. The aviation FTE mentions that they offer services around the clock in different languages. Further, their customer support team works closely with the sales team to solve customer issues. Road DFFs offer a detailed FAQ, and dedicate a person to the participant for eventual issues. InstaFreight allows opening a ticket at the first instance and facilitates checking the ticket status at any time (thus the services are standardized and automated). Hence, different types of services appear to be aligned to the participants requirements.

The adaptation of the exchanges to new participants will be a continuous process, but higher automation in services to improve the exchanges' capability to solve communication issues is crucial.

Thus, the maturity level of all exchanges is at least beyond ad hoc actions, hence Level 2.

(b) The "Process automation" practice relates to the process of automating to ensure data consistency, data availability and data transfers with participants and partner ICT systems to improve the use of product and services, e.g., through technical innovation. The integration of a participant's system strengthens the participant's loyalty towards the exchange. The performance can be measured by percentage of integration of exchange and participant and partner systems since the last period. In absence of public data the process for managing process automation was considered the proxy maturity assessment criteria.

All exchanges appear to have their data centers and organize for secure data transmission. Access to data on subscription appears to ensure that only relevant data is made available to the participants on the exchange. Regarding the extent of automation, multimodal FTE Freightos mentions having imported thousands of Excel sheets in initial years regarding thousands of freight forwarders, into their large database to automate the matching process. Multimodal DFFs, e.g., Flexport, mentions that about $90 \%$ of their participants agree being able to make better supply chain decisions due to 
automated processes and data on participant made available on the exchanges. Forto mentions that their focus on increasing automation and integration level with their partners is key to improving the transparency and service reliability. Process automation for the aviation FTE is possibly facilitated by standardized processes through IATA in the aviation industry. For these exchanges, due to their global focus, integration of systems (e.g., through APIs) is an ongoing process. Such information was not found on the road DFFs. Presumably, this is currently not their focus. Nevertheless, the 24X7 availability of information and transparency of information anytime is an indication that they are working on process automation.

Therefore, the maturity of multimodal FTE and DFFs are assessed at Level 3, that of aviation at Level 2 and road DFFs at Level 2.

\section{Conclusions}

This paper is structured by two research questions. It explores the state of online exchanges in the EU freight transportation industry (other than rail) for the matching of supply and demand in single transport mode and multimodal services (RQ1). The analysis aimed to identify emerging trends and significant characteristics (related to, e.g., the market niche, product differentiation) of successful exchange business models. Next, it focuses on key learnings regarding maturity of matching practices that enable the online exchanges to organize single as well as multimodal services in the freight transportation industry (RQ2). Such learnings can be valuable for future multimodal online exchanges organizing rail and road transportation in the EU. This section formulates the conclusions on the analysis and related points of discussion.

The first conclusion is that the earlier specified conceptual framework OEMF [10] appears very supportive in evaluating and comparing online exchanges in the freight transportation industry. The consequent use of the elaborated KPIs support the data collection and the evidence based in-depth assessment of various practices of online exchanges in freight transport. Clearly, a key challenge for the in-depth analysis is the limited availability of publicly accessible data. In absence of such data, sometimes proxy indicators for assessment of the maturity levels of the OEMF's criteria had to be used. We interviewed experts with broad and inner circle knowledge on this subject for face validity of the desk analyses.

The main conclusion on RQ1 is that strong competition in unrestricted online exchanges in the freight industry exits. Such exchanges are catering transport at EU and global level in single transport modes (air, road) as well as multimodal (ocean, air, and road). These exchanges are third party, profit-based startups that are establishing themselves in specific (though a variety of) market niches in a currently very fragmented freight transport market. The exchanges do so by using ICT applications for (i) collecting and digitizing rich volumes of data to organize a fast matching between the supply and demand side, (ii) providing visibility of transport services for participants, and (iii) even organizing tailor-made services by integrating a participant's system with the exchange's one.

The key learnings addressed in RQ2 focuses on maturity of unrestricted exchanges. In relation to this, a steady development in the direction of more mature exchanges can be observed. This becomes visible in terms of, e.g., facilitating competition through dynamic price discovery and communication of price signals as reference to the freight market, and fast and algorithm-based allocation of service offers to the demand side (based on anonymity on both sides during matching). Regarding the practices in the market related KPA, the analysis shows that in order to grow, exchanges define a clear market focus with the goal to ultimately being able to deliver the promised benefits to the participants on both sides. In this context, it appears that currently the economic and social benefits from matching (often related to reducing operational inefficiencies that participants seek) seem to override the environmental benefits; e.g., reducing $\mathrm{CO}_{2}$ emissions is not yet a manifest market demand. This reduction appears to be more of a network effect e.g., through the optimal use of empty transport capacity. In this respect, the complex cross border and fragmented freight transport business provides a context that is difficult to deal with. Complexity in the case of cross-border freight transport is notably due to 
possible differences in technical requirements as well as regulatory differences regarding, e.g., labor, environment, infrastructure use, or liability arrangements.

Exchanges show maturity by defining, e.g., standardized products and services across various transport modes that enable capturing, visualizing, and utilizing data for continually optimizing the participant's operational processes in multimodal transport chains (e.g., from sales process to completion of actual transport service). The ability to successfully offer services that are based on real time dynamic price discovery for competing demands, reflects the responsiveness of exchanges to continuously make the necessary underlying strategic choices regarding the use of state-of-the-art ICT, the design of effective matching algorithms and the organization of support services. This is essential for understanding and catering to the dynamically changing participant needs. Where these needs regard cross-border freight transportation, exchanges guide participants in prioritizing issues for operationally solving related complexities. To enrich such support, multimodal online exchanges therefore seek innovation by integrating participants' systems to the exchange system, by moving to adjacent markets (create interfaces with other exchanges to enhance the network effects), and by constantly influencing (e.g., cross-border) markets, e.g., by communicating price signals transparently. The summarized learning is that, by nurturing and actively developing such flexible, responsive, and active capability, these exchanges retain their competitive edge in the freight transportation market.

Next, the learnings regarding the operational KPA are discussed. All studied exchanges appeared to be capable of standardizing, monitoring, and controlling their operational processes and related policies. This is the result of a constant strong focus on process automation to optimize exchange operations (e.g., faster checking of credentials of participants, hassle free payments and debt collection). This, in turn, leads to the conclusion that training and learning (to update with market and ICT developments) and continually improving the matching algorithm to speed up the finalizing of transactions, are important for maturity growth. Further, creating full trust and protecting participants from misuse of (their) data, e.g., by matching anonymously, appears to be a crucial condition for success.

Finally, what can be learned regarding practices in the technical KPA? An important learning for the $24 X 7$ real time support organization is that the focus should be on building internal capacities crucial to delivering services tailored to the requirements of participants. Crucial capabilities relate to, e.g., knowledge on machine learning and artificial intelligence, developing algorithms, domain knowledge, and market contacts. Moreover, successful exchanges show a relatively high level of maturity in organizing availability, security, and reliability of data by integrating participants' and partners' ICT systems to that of the exchange. In providing such interfaces costs are saved for ICT development for the participants and barriers reduced for potential participants to adopt the exchange. Ultimately, exchanges can either organize these practices themselves or choose to (partly) outsource them to partners by forming a relationship in such a manner that the core competence of business remains with the exchange, which basically implies to be able to manage the risks arising from dependencies and to further improve services for the participants. The presented analysis inevitably generates new questions for further research. In regard to the maturity assessment, it is challenging to investigate why the maturity levels of practices in operational and technical KPA lag behind the maturity of practices in the market-related KPA. With regard to multimodal exchanges, the question is still unanswered as to whether the exchanges can really integrate rail freight transport with road transport services within the EU; what are the niches where this can be successfully realized? Finally: does the conceptual framework of OEMF provide a sufficiently elaborated way of thinking to support the transition in business models of online exchanges and their participants in favor of a more sustainable freight transport system?

Author Contributions: A.J., with the help of R.v.d.H. designed the scope, conceptualized, and wrote the paper; A.J. collected data, performed interviews and carried out the analysis; R.v.d.H. provided relevant feedback and editing; V.M. and D.B. contributed to the feedback on scope and final draft. All authors have read and agreed to the published version of the manuscript.

Funding: This research and the authors received no external funding. 
Acknowledgments: The authors are grateful to all the participants who have taken time to give an interview and provide examples and insights that were considered useful for this research.

Conflicts of Interest: The authors declare no conflict of interest.

\section{References}

1. EUROSTAT. Modal Split of Freight Transport: Online Data Code Tran_hv_Frmod; European Commission: Brussels, Belgium, 2020.

2. Manners-Bell, J.; Lyon, K. The Logistics and Supply Chain Innovation Handbook: Disruptive Technologies and New Business Models, 1st ed.; Kogan Page: London, UK, 2019.

3. Bain, J.S. Industrial Organization; Wiley: New York, NY, USA, 1959.

4. Freudenreich, B.; Lüdeke-Freund, F.; Schaltegger, S. A Stakeholder Theory Perspective on Business Models: Value Creation for Sustainability. J. Bus. Ethics 2019. [CrossRef]

5. Gordijn, J.; Akkermans, H.; van Vliet, H. What's in an electronic business model? In International Conference on Knowledge Engineering and Knowledge Management; Springer: Berlin/Heidelberg, Germany, 2000; pp. 257-273.

6. Bouwman, H.; Zhengjia, M.; van der Duin, P.; Limonard, S. A business model for IPTV service: A dynamic framework. Info 2008, 10, 22-38. [CrossRef]

7. Evans, D.S.; Schmalensee, R.; Noel, M.D.; Chang, H.H.; Garcia-Swartz, D.D. Platform Economics: Essays on Multi-Sided Businesses; Evans, D.S., Ed.; Competition Policy International: Chicago, IL, USA, 2011. Available online: https://ssrn.com/abstract=1974020 (accessed on 22 July 2020).

8. Paulk, M.C.; Curtis, B.; Chrissis, M.B.; Weber, C.V. Capability Maturity Model for Software (Version 1.1) (Tech. No. CMU/SEI-93-TR-024). 1993. Available online: https://resources.sei.cmu.edu/library/asset-view.c fm?assetid=11955 (accessed on 24 July 2020).

9. Jain, A.; Bruckmann, D.; van der Heijden, R.E.; Marchau, V.A. Towards rail-related multimodal freight exchange platforms: Exploring regulatory topics at EU level. Compet. Regul. Netw. Ind. 2019, 20, 138-163. [CrossRef]

10. Jain, A.; Bruckmann, D. Application of the principles of energy exchanges to the rail freight sector. Transp. Res. Rec. J. Transp. Res. Board 2017, 2609, 28-35. [CrossRef]

11. Jain, A. Developing Online Freight Transport Exchanges: Theoretical Insights and Conceptual Framing; Working Paper WP-Jain-20-01; Radboud Repository: Nijmegen, The Netherlands, 2020.

12. Chang, H.-L.; Easley, R.F.; Shaw, M.J. A comparative study of exchange and aggregation models in the B2B e-marketplace. Inf. Syst. E-Bus. Manag. 2003, 1, 213-228. [CrossRef]

13. Van Duin, R. Logistics Concept Development in Multi-Actor Environments. Aligning Stakeholders for Successful Development of Public/Private Logistics Systems by Increased Awareness of Multi-Actor Objectives and Perceptions. Ph.D. Thesis, Delft University of Technology, Delft, The Netherlands, 2012. [CrossRef]

14. Moroz, M.I.; Nicu, C.C.; Pavel, I.D.; Pólkowski, Z.D. The Transformation of Logistics into E-logistics on the Example of Electronic Freight Exchange. Zesz. Nauk. DWSPiT Studia Nauk Tech. 2014, 3, 111-128.

15. Poliak, M.; Šimurková, P. Harmonization of Market Conditions in Provision of Freight Forwarding. In MATEC Web Conferences; EDP Sciences: Les Ulis, France, 2017; Volume 134, p. 00048. [CrossRef]

16. EU Committee. Online Platforms and the Digital Single Market: 10th Report of Session 2015-2016 (House of Lords). 2016. Available online: https://publications.parliament.uk/pa/ld201516/ldselect/ldeucom/129/129.pdf (accessed on 24 July 2020).

17. Elbert, R.; Gleser, M. Digital Forwarders. In Logistics Management; Springer: Cham, Switzerland, 2019; pp. 19-31. [CrossRef]

18. Carlsson, B. Industrial dynamics: A framework for analysis of industrial transformation. Rev. Econ. Ind. 1992, 61, 7-32. [CrossRef]

19. Carlsson, B. Industrial Dynamics: A Review of the Literature 1990-2009. Ind. Innov. 2016, 23, 1-61. [CrossRef]

20. Rochet, J.-C.; Tirole, J. Platform competition in two-sided markets. J. Eur. Econ. Assoc. 2003, 1, 990-1029. [CrossRef]

21. Choudary, S.P. Platform Scale: How an Emerging Business Model Helps Startups Build Large Empires with Minimum Investment; Platform Thinking Labs Pte. Ltd.: Singapore, 2015; ISBN 9789810967581.

22. Parker, G.; Van Alstyne, M.; Choudary, S.P. Platform Revolution: How Networked Markets Are Transforming the Economy and How to Make Them Work for You, 1st ed.; W.W. Norton \& Co.: New York, NY, USA, 2016. 
23. Coenen, J.; van der Heijden, R.; van Riel, A.C.R. Making a Transition toward more Mature Closed-Loop Supply Chain Management under Deep Uncertainty and Dynamic Complexity: A Methodology. Sustainability 2019, 11, 2318. [CrossRef]

24. Tirole, J. Economics for the Common Good; Rendall, S., Translator; Princeton University Press: Princeton, NJ, USA, 2017; ISBN 9780691175164.

25. Endemann, P. Online rail freight exchange (ORFE): Better rail competitiveness and acceptance. In Integrated Spatial and Transport Infrastructure Development, Contribution to Economics Book Series; Drewello, H., Scholl, B., Eds.; Springer: Cham, Switzerland, 2016; pp. 13-228. [CrossRef]

26. Seeßle, P. Nachhaltige Beschaffung auf digitalen Plattformen am Beispiel logistischer Dienstleistungen-Analyse der Möglichkeiten für Einkäufer und Auswirkungen anhand der drei Dimensionen der Nachhaltigkeit. In Nachhaltiges Beschaffungsmanagement; Springer Gabler: Wiesbaden, Germany, 2019; pp. 371-387. [CrossRef]

27. Chan, T.; Schöndorfer, S.; Schröder, F.; Sønderby, M.; Riedl, J. The Digital Imperative in Freight Forwarding. 13 November 2018. Available online: https://www.bcg.com/publications/2018/digital-imperative-freight-for warding (accessed on 12 February 2020).

28. Tracxn. Freight Forwarding Marketplace Market Report; Tracxn Technologies Private Limited: Bengaluru, India, August 2019. Available online: https://tracxn.com/d/reports-bm/Freight-Forwarding-Marketplace-MarketReport (accessed on 13 February 2020).

29. Hentschel, T.; Krotki, K.; Haas, D.; Umetova, N.; Farkas, M.; Semmelmann, C. Digitalization in Freight Forwarding-Beyond the Platform Hype; Issue 08/2019; Deliotte: London, UK, 2019. Available online: https://www2.deloitte.com/content/dam/Deloitte/de/Documents/consumer-business/Deloitte_\%20 Digitalization\%20in\%20freight\%20forwarding_PoV.pdf (accessed on 12 February 2020).

30. Adams, W.C. Conducting Semi-Structured Interviews. In Handbook of Practical Program Evaluation; John Wiley \& Sons: Hokboken, NJ, USA, 2015; pp. 492-505. [CrossRef]

31. Göpfert, I.; Seeßle, P. Innovative Startups in der Logistikbranche-Eine Betrachtung der neuen Marktteilnehmer und empirische Erkenntnisse einer Fragebogenstudie. Logist. Zuk. Logist. Future 2018, 253-280. [CrossRef]

32. Carnarius, J. Freight Trains Are Steaming from Asia to Europe. 28 March 2017. Available online: https: //forto.com/en/blog/freight-rails-steaming-asia-europe/ (accessed on 30 July 2020).

33. Freightos (Tradeos, Ltd.). The Only Daily and IOSCO-Compliant Container Freight Index, Ready for Index-Linked Contracts and Derivatives; Freightos Baltic Index; Freightos (Tradeos, Ltd.): Hong Kong, China, 2020. Available online: https://fbx.freightos.com/ (accessed on 22 July 2020).

34. ADSp. Allgemeine Deutsche Spediteurbedingungen; Der DSLV. January 2017. Available online: https://www. dslv.org/dslv/web.nsf/gfx/F486B2D03DC404C6C12583F3003EC7AC/\$file/DSLV-ADSp-2017-EN.pdf (accessed on 19 June 2020).

35. Dietrich, A.; Fiege, F. Digitale Transformation des Speditionsgeschäfts umfasst mehr als Spedition 4.0. Wirtsch. Manag. 2017, 9, 36-45. [CrossRef]

36. The MathWorks, Inc. Freightos Performs Big Data Analytics for Online Freight Logistics with MATLAB and Google BigQuery; The MathWorks, Inc.: Natick, MA, USA, 2020. Available online: https://ch.mathworks.com/de/company/user_stories/freightos-performs-big-data-analytics-for-online-frei ght-logistics-with-matlab-and-google-bigquery.html (accessed on 26 July 2020).

37. D’Ippolito, B.; Messeni Petruzzelli, A.; Panniello, U. Archetypes of incumbents' strategic responses to digital innovation. J. Intellect. Cap. 2019, 20, 662-679. [CrossRef]

38. Artificial Intelligence (AI) in the Global Freight Transportation Industry, Forecast to 2025 (ID: 4968377). Research and Markets. January 2020. Available online: http://www.researchandmarkets.com (accessed on 30 July 2020).

39. Models of Transportation Electronic Marketplaces: An Empirical Survey. Annals of Maritime Studies. J. Marit. Transp. Sci. 2004, 42, 77-92.

40. Freightos (Tradeos, Ltd.). Why Freightos; Freightos (Tradeos, Ltd.): Hong Kong, China, 2020. Available online: https://www.freightos.com/marketplace/ (accessed on 22 July 2020).

41. Flexport Inc. The Operating System for Global Trade; Flexport Inc.: San Francisco, CA, USA, 2020. Available online: https://www.flexport.com/our-vision/ (accessed on 24 April 2020).

42. Struck, F. How to Change Your Freight Forwarder in Less Than 4 Hours, Saving Up to $€ 35,000$ Per Year. 15 July 2019. Available online: https:/forto.com/de/blog/how-to-change-your-freight-forwarder-in-less-tha n-4-hours-saving-up-to-e-35000-per-year/ (accessed on 24 July 2020). 
43. Cargo.one GmbH. Why Freight Forwarders of All Sizes Use Cargo.One; Cargo.one GmbH: Berlin, Germany, 2020. Available online: https://www.cargo.one/customers (accessed on 24 March 2020).

44. Sennder GmbH. Our Vision; Sennder GmbH: Berlin, Germany, 2020. Available online: https://www.sennder. com/de/about-us (accessed on 13 July 2020).

45. Cargonexx GmbH. Cargonexx. Available online: https://www.cargonexx.com/en/about-us (accessed on 26 July 2020).

46. InstaFreight GmbH. About the Digital Freight Forwarding Company; InstaFreight GmbH: Berlin, Germany, 2020. Available online: https://www.InstaFreight.de/en/about-us (accessed on 13 July 2020).

47. IKEA Range and Supply. Breaking the Trend: IKEA Reports a Decrease in Climate Footprint. 27 February 2020. Available online: https://newsroom.inter.ikea.com/news/breaking-the-trend--ikea-reports-a-decrease -in-climate-footprint/s/309a4361-6968-4bda-8542-a3cbc26dcd6f?cultureSeoName=GLOBAL (accessed on 22 June 2020).

48. Freightos (Tradeos, Ltd.). Carbon Emissions in Logistics: The Road to Green International Freight; Freightos (Tradeos, Ltd.): Hong Kong, China, 2020. Available online: https://www.freightos.com/de/freight-resources /green-freight-means-making-a-difference/ (accessed on 22 July 2020).

49. Henten, A.H.; Windekilde, I.M. Transaction costs and the sharing economy. Info 2016, 18, 1-15. [CrossRef]

50. Freightos (Tradeos, Ltd.). Freightos Pricing; Freightos (Tradeos, Ltd.): Hong Kong, China, 2020. Available online: https://www.freightos.com/pricing/ (accessed on 22 July 2020).

51. Freightos (Tradeos, Ltd.). Freightos Master Services Agreement; Freightos (Tradeos, Ltd.): Hong Kong, China, 2020. Available online: https://www.freightos.com/freightos-master-services-agreement/ (accessed on 22 July 2020).

52. Flexport Inc. Flexport Software Terms E Conditions; Flexport Inc.: San Francisco, CA, USA, 2020. Available online: https://www.flexport.com/terms-and-conditions/software_terms_and_conditions (accessed on 24 April 2020).

53. Forto GmbH. Data Privacy; Forto GmbH: Berlin, Germany, 2020. Available online: https://forto.com/en/priva cy-policy-2/ (accessed on 24 July 2020).

54. Cargonexx GmbH. General Terms and Conditions of CARGONEXX GmbH; Cargonexx GmbH: Hamburg, Germany, May 2020. Available online: https://www.cargonexx.com/en/terms (accessed on 26 July 2020).

55. InstaFreight GmbH. General Terms and Conditions for Forwarding Services of InstaFreight GmbH (Customer GTC); InstaFreight GmbH: Berlin, Germany, 6 July 2020. Available online: https://cdn.InstaFreight.de/de-live/orig inal_kunden-agb_en_3W5U8.pdf (accessed on 13 July 2020).

56. Sennder GmbH. Terms \& Conditions; Sennder GmbH: Berlin, Germany, 2020. Available online: https: //www.sennder.com/terms-conditions (accessed on 13 July 2020).

57. Boisseleau, F. The Role of Power Exchanges for the Creation of a Single European Electricity Market: Market Design and Market Regulation. Ph.D. Thesis, Delft University, Delft, The Netherlands, January 2004. Available online: http://resolver.tudelft.nl/uuid:adaa3685-ff74-4ad6-b765-752f1a673c4c (accessed on 31 October 2018).

58. Johnson, E. New Freightos Funding Propels Indices and Associated Futures. JOC.Com. 17 August 2018. Available online: https://www.joc.com/maritime-news/freightos-new-funding-propels-freight-indices-andassociated-futures_20180917.html (accessed on 30 July 2020).

59. Freightos (Tradeos, Ltd). The Complete Amazon FBA Shipping Guide; Freightos (Tradeos, Ltd.): Hong Kong, China, 2020. Available online: https://www.freightos.com/de/freight-resources/amazon-fba-freight-shipping/ (accessed on 15 July 2020).

60. Flexport Inc. Shipping to Amazon FBA. 2020. Available online: https://de.flexport.com/help/category/shippi ng-to-amazon-fba/ (accessed on 24 July 2020).

61. Forto GmbH. FBA Mit Forto; Forto GmbH: Berlin, Germany, 2020. Available online: https://forto.com/en/ama zon-fba/ (accessed on 23 July 2020).

62. Gruchmann, T.; Pratt, N.; Eiten, J.; Melkonyan, A. 4PL Digital Business Models in Sea Freight Logistics: The Case of FreightHub. Logistics 2020, 4, 10. [CrossRef]

63. Air Cargo News. Freightos WebCargo Acquires Air Freight Bazaar India; DVV Media Group: Hamburg, Germany, 1 April 2019. Available online: https://www.aircargonews.net/business/acquisitions/freightos-webcargo-ac quires-air-freight-bazaar-india/ (accessed on 15 July 2020). 
64. DVZ. Freighthub und Maersk Kooperieren bei Seefrachtbuchungen; Deutsche Verkehrs-Zeitung: Hamburg, Germany, 19 December 2019. Available online: https://www.dvz.de/rubriken/see/detail/news/freighthub-u nd-maersk-kooperieren-bei-seefrachtbuchungen.html (accessed on 15 July 2020).

65. Sennder GmbH. Joined Forces in May 2020; Sennder GmbH: Berlin, Germany, May 2020. Available online: https://www.sennder.com/everoad (accessed on 13 July 2020).

66. Wiener, E. Four Expert Tips That Built a $\$ 25$ Million Amazon FBA Business. Available online: https://www.fr eightos.com/freight-resources/masters-of-trade-episode-01-eytan-wiener-quantum-networks/ (accessed on 24 July 2020).

67. Eynon, J. Freight APIs Are Transforming Shipping and Transportation. 19 March 2018. Available online: https://www.evanstrans.com/blog/freight-apis-transforming-shipping-transportation (accessed on 15 July 2020).

68. Flexport Inc. We're an Extension of Your Logistics Team; Flexport Inc.: San Francisco, CA, USA, 2020. Available online: https://www.flexport.com/our-service-model/ (accessed on 24 April 2020).

Publisher's Note: MDPI stays neutral with regard to jurisdictional claims in published maps and institutional affiliations.

(C) 2020 by the authors. Licensee MDPI, Basel, Switzerland. This article is an open access article distributed under the terms and conditions of the Creative Commons Attribution (CC BY) license (http://creativecommons.org/licenses/by/4.0/). 